\title{
Evaluation of life cycle inventory data for recycling systems
}

Brogaard, Line Kai-Sørensen; Damgaard, Anders; Jensen, Morten Bang; Barlaz, Morton ; Christensen, Thomas Højlund

Published in:

Resources, Conservation and Recycling

Link to article, DOI:

10.1016/j.resconrec.2014.03.011

Publication date:

2014

Document Version

Peer reviewed version

Link back to DTU Orbit

Citation (APA):

Brogaard, L. K-S., Damgaard, A., Jensen, M. B., Barlaz, M., \& Christensen, T. H. (2014). Evaluation of life cycle inventory data for recycling systems. Resources, Conservation and Recycling, 87, 30-45.

https://doi.org/10.1016/j.resconrec.2014.03.011

\section{General rights}

Copyright and moral rights for the publications made accessible in the public portal are retained by the authors and/or other copyright owners and it is a condition of accessing publications that users recognise and abide by the legal requirements associated with these rights.

- Users may download and print one copy of any publication from the public portal for the purpose of private study or research.

- You may not further distribute the material or use it for any profit-making activity or commercial gain

- You may freely distribute the URL identifying the publication in the public portal

If you believe that this document breaches copyright please contact us providing details, and we will remove access to the work immediately and investigate your claim 


\title{
Evaluation of life cycle inventory data for recycling systems
}

\author{
Line K. Brogaard*1, Anders Damgaard ${ }^{1}$, Morten B. Jensen ${ }^{1}$, \\ Morton Barlaz ${ }^{2} \&$ Thomas H. Christensen ${ }^{1}$ \\ ${ }^{1}$ Department of Environmental Engineering \\ Building 115, Technical University of Denmark \\ DK-2800 Kongens Lyngby, Denmark \\ ${ }^{2}$ Department of Civil, Construction, and Environmental Engineering \\ Box 7908 North Carolina State University \\ Raleigh, NC 27695-7908 \\ United States \\ * Corresponding author \\ Department of Environmental Engineering \\ Building 115 \\ Technical University of Denmark \\ 2800 Kongens Lyngby, Denmark \\ Phone: +45 45251488 \\ Fax: +45 45932850 \\ E-mail: $\underline{\text { lksb@env.dtu.dk }}$
}

"NOTE: this is the author's version of a work that was accepted for publication in Resources, Conservation and Recycling journal. Changes resulting from the publishing process, such as peer review, editing, corrections, structural formatting, and other quality control mechanisms may not be reflected in this document. Minor changes may have been made to this manuscript since it was accepted for publication. A definitive version is published in Resources, Conservation and Recycling, vol 87, pp 30-45, doi: 10.1016/j.resconrec.2014.03.011” 


\begin{abstract}
This paper reviews databases on material recycling (primary as well as secondary production) used in life cycle assessments (LCA) of waste management systems. A total of 366 datasets, from 19802010 and covering 14 materials, were collected from databases and reports. Totals for $\mathrm{CO}_{2}-$ equivalent emissions were compared to illustrate variations in the data. It was hypothesised that emissions from material production and the recycling industry had decreased over time due to increasing regulation, energy costs and process optimisation, but the reported datasets did not reveal such a general trend. Data representing the same processes varied considerably between databases, and proper background information was hard to obtain, which in turn made it difficult to explain the large differences observed. Those differences between the highest and lowest estimated $\mathrm{CO}_{2}$ emissions (equivalents) from the primary production of newsprint, HDPE and glass were 238, 443 and $452 \%$, respectively. For steel and aluminum the differences were 1,761 and 235\%, respectively. There is a severe lack of data for some recycled materials; for example, only one dataset existed for secondary cardboard. The study shows that the choice of dataset used to represent the environmental load of a material recycling process and credited emissions from the avoided production of virgin materials is crucial for the outcome of an LCA on waste management. Great care and a high degree of transparency are mandatory, but advice on which datasets to use could not be determined from the study. However, from the gathered data, recycling in general showed lower emission of $\mathrm{CO}_{2}$ per kg material than primary production, so the recycling of materials (considered in this study) is thus beneficial in most cases.
\end{abstract}

Keywords: Life cycle inventory (LCI) databases, Waste recycling, Plastics, Paper, Cardboard, Glass, Aluminum, Steel, Life cycle assessment (LCA), $\mathrm{CO}_{2}$ emission 


\section{Introduction}

The reuse and recovery of resources from municipal waste contribute to sustainable development, and in the future, together with waste prevention, they will be a strong focus in many parts of the world (European Commission, 2011; Hoornweg et al., 2013). Companies and public authorities will be forced to use life cycle approaches to identify the best options for future waste management systems, including recycling. To carry out a life cycle assessment (LCA), there is a need for life cycle inventory (LCI) data to ensure a representative assessment. LCI data on waste management processes involved in recycling, including source separation, collection, transport and upgrading of recyclables, are readily available (for example, Merrild et al., 2012). However, LCI data on the actual industrial recycling of recovered materials can be found in external databases. LCI data on the remanufacturing of materials recovered from solid waste must include the environmental load of the manufacturing process employed to convert recovered materials into a new material (henceforth called 'secondary'), as well as the environmental load credited as a result of avoiding virgin material production (henceforth called 'primary'). In 2006, the UK Waste and Recovery Action Programme published a hefty review of LCA studies on recycling versus incineration and landfilling (WRAP, 2006). The review presented variations in the results taken from the studies, but did not look into the inventories behind the LCAs.

Many databases containing remanufacturing LCI data are available. However, selecting the right dataset out of the many published since 1980 for a specific LCA model is not particularly straightforward despite the existence of various guidelines (ISO, 2006; European Commission, 2010). ISO standard 14044 (ISO, 2006) and the ILCD Handbook (European Commission, 2010) describe the data quality requirements for LCIs. However, data quality indicators are typically not documented in the available datasets. There are a large number of waste-specific LCA models (e.g. EASEWASTE, WRATE, MSW-DST) (Gentil et al., 2010) as well as generic LCA models (e.g. SIMAPRO, GaBi, Umberto) and databases (e.g. Ecoinvent, US LCI, ELCD) in use, but there has been little discussion in the literature as to what dataset is most appropriate for a given LCA study, and no comparison has been made between these different data sources.

To assess data quality used in LCAs, Weidema and Wesnaes (1996) provided the pedigree matrix. This system ensures an overview of the relevance of a dataset for a given assessment. The matrix is used for LCA studies, and the scoring of the data is linked to the scope of the study. Factors to consider when assessing data quality include the age of the data, the level of detail in the background description and the technical and geographical representativeness.

The goal of this study was to provide an overview of the challenges involved in choosing representative datasets for material recycling and virgin material production processes. Challenges come in the form of the transparency of databases and documentation on background information for datasets. For a quantitative assessment of multiple databases, $\mathrm{CO}_{2}$-equivalents was selected as an indicator parameter for environmental load, and its value was used to compare data across a range of recyclable materials found in available data sources. 


\section{Databases and choosing datasets}

LCI databases on material recycling processes come from a variety of sources, the major ones of which are large public and commercial databases such as Ecoinvent (2013), PE International (2013), U.S. Life Cycle Inventory Database (US LCI, 2013) and the European reference Life Cycle Database (ELCD, 2013). These databases may also be accessed through commercial LCA modelling tools, including Simapro (PRé, 2013), Umberto (Ifu Hamburg, 2013) and GaBi (PE International, 2013). In addition, there are a number of smaller models dedicated to specific applications (municipal waste, packaging materials, fuels, biofuels, etc.) which have accompanying databases (e.g. EASETECH (Clavreul et al., 2014) and SWOLF (Levis et al., 2013)).

A total of 26 databases and sources were identified for this study, including the 366 material datasets for 14 materials presented in Table 1 . Another 46 potential sources of LCI data were identified but not included due to language issues, closed websites, a prohibitive fee structure or because the data were not fully compatible with this study. The authors have licences for Simapro and $\mathrm{GaBi}$ - LCA tools which give access to many of the databases. No other licences were bought, and therefore some available databases were not included, even though these might be of good quality and up to date (e.g. Umberto (Ifu Hamburg, 2013)). All data sources were identified by searching the internet, starting from the ELCD homepage which provides a comprehensive list of databases and sources. Scientific search engines (Web of Knowledge (2013) etc.) were also used to find scientific papers and relevant research reports.

\subsection{Data selection criteria}

The focus of this study was on data representing material production based on primary and secondary materials, including fibre (copy paper, cardboard, corrugated cardboard, newsprint), plastics (HDPE, LDPE, LLDPE, PET, PVC, PS, and PP), steel, aluminum and glass. The criteria for inclusion were that the material should be pure in an industrial context and preferably not a product, i.e. a steel ingot versus metal cans. In some cases products were included, for example in the case of glass, since most recycled glass comes from containers used for food and beverages.

Datasets were selected on the basis that it was possible to quantify $\mathrm{CO}_{2}$-equivalent emissions, as this parameter was used as an indicator for dataset comparisons. $\mathrm{CO}_{2}$ emission levels also provide an indication of the type of energy used in the dataset; for instance, high $\mathrm{CO}_{2}$ emissions would indicate the high consumption of resource-demanding materials or of fossil energy. Datasets that were outliers in terms of $\mathrm{CO}_{2}$-equivalents were specifically scrutinised to identify special conditions, as discussed below. $\mathrm{CO}_{2}$-equivalents for biogenic $\mathrm{CO}_{2}$ were considered to be zero, which is consistent with the definition for modelling biogenic carbon in waste management systems (Christensen et al., 2009; Muñoz et al., 2012).

Data documentation should describe the origin and age of the data, whether the data were measured, calculated or estimated, what was excluded, a careful description of the system boundaries and the organisation responsible for the data development. Unfortunately, complete documentation was never available and datasets with partial documentation were included. 
Table 1: List of databases, reports and papers considered in this study. All sources are available in English.

\begin{tabular}{|c|c|c|c|}
\hline \# & Reference & Access & Notes \\
\hline 1 & Aluminum Association (2010) & Free report & - \\
\hline 2 & Arena et al. (2004) & Free paper & - \\
\hline 3 & Avfall Norge (2009) & Free report & - \\
\hline 4 & BUWAL (1990) & Paid licence needed & No longer included in Simapro databases \\
\hline 5 & $\begin{array}{l}\text { Corrugated Packaging Allianc- } \\
\text { es (2009) }\end{array}$ & Free report & - \\
\hline 6 & EASEWASTE (2010) & Training course & - \\
\hline 7 & Ecoinvent (2013) & $\begin{array}{l}\text { Paid licence needed, or licence for } \\
\text { Simapro or Gabi }\end{array}$ & - \\
\hline 8 & ELCD (2012) & $\begin{array}{l}\text { Free download of data from } \\
\text { homepage }\end{array}$ & - \\
\hline 9 & ETH-ESU (1996) & Paid licence needed for Simapro & No longer included in Simapro databases \\
\hline 10 & EUROFER (2000) & $\begin{array}{l}\text { Paid licence needed for } \mathrm{GaBi} \text {, or } \\
\text { see ELCD homepage }\end{array}$ & $\begin{array}{l}\text { Contains only steel processes. Processes } \\
\text { are used in the ELCD database. }\end{array}$ \\
\hline 11 & European Commission (2001) & Free report & - \\
\hline 12 & EAA (2005) & Paid licence needed for $\mathrm{GaBi}$ & - \\
\hline 13 & Franklin USA (1995) & Paid licence needed for Simapro & - \\
\hline 14 & GEMIS (1990) & Download from homepage & - \\
\hline 15 & IDEMAT (2001) & Paid licence needed for Simapro & Closed but can be found through Simapro \\
\hline 16 & IFEU (2009) & Free report & - \\
\hline 17 & Industry data 2.0 (2013) & Paid licence needed for Simapro & $\begin{array}{l}\text { Data collected by industry associations, } \\
\text { e.g. Plastics Europe. }\end{array}$ \\
\hline 18 & $\begin{array}{l}\text { International Aluminum Insti- } \\
\text { tute (2007) }\end{array}$ & Free report & - \\
\hline 19 & interseroh (2007) & Free report & - \\
\hline 20 & PlasticEurope (2005) & $\begin{array}{l}\text { Free download from homepage or } \\
\text { access via Simapro or GaBi }\end{array}$ & Plastic Europe was earlier called APME \\
\hline 21 & US EPA (1998) & Free report & $\begin{array}{l}\text { The WAste } \\
\text { Reduction Model (WARM) }\end{array}$ \\
\hline 22 & US EPA (2003) & Free report & - \\
\hline 23 & US LCI (2013) & Free download from homepage & - \\
\hline 24 & WorldSteel (2007) & \begin{tabular}{|l|} 
Paid licence needed to $\mathrm{GaBi}$ \\
\end{tabular} & - \\
\hline 25 & WRAP (2008) & Free report & $\begin{array}{l}\text { Data available in Ecoinvent from AP- } \\
\text { ME/Plastic Europe }\end{array}$ \\
\hline 26 & Återvinningsindustrierna (2002) & Free report & - \\
\hline
\end{tabular}

\subsection{Representative data}

A representative dataset is one that embodies the assessed process, or the closest similar process, and detailed knowledge in this respect is required to know which process is most illustrative. This issue cannot be solved by applying Weidema and Wesnaes's (1996) pedigree matrix, though. For example, while HDPE manufacturing processes may be similar globally, the same cannot be said 
for paper, where each manufacturing facility tends to be unique and processes a specific set of fibre types that may vary over time. This makes it difficult to model a typical national average paper plant while a site-specific of an individual paper plant can be well-defined.

In the context of recycling, it is important to identify datasets that reflect industrial production processes where a good mix of scrap materials and virgin materials is used. Such processes are commonplace, but of course they do not provide separate data on virgin and recycled material manufacturing. Good documentation is critical to determine the net difference in increasing, for example, scrap recycling (actual process substituting and the actual substitution ratio). The energy used in production, in particular electricity, is usually a key contributor to an LCI. Thus, the documentation should be detailed about energy use, particularly in view of quantity and quality. The impacts caused by using electricity and applying heat vary a great deal between countries because of the different mix of energy sources. Therefore, it is important to use non-aggregated data in LCI datasets, in order to identify the contribution made by the energy use and potentially to change the process if the dataset is to be used in a different region with a different electricity fuel mix.

\subsection{Description of material recovery from municipal solid waste for recycling}

This section provides an overview of the key characteristics of the materials that are typically recycled from solid waste and are considered in this study, including copy paper, newsprint, cardboard, corrugated cardboard, container glass, steel, aluminum and plastics (high density polyethylene (HDPE), low density polyethylene (LDPE), linear low density polyethylene (LLDPE), polyethylene terephthalate (PET), polypropylene (PP), polyvinylchloride (PVC) and polystyrene (PS)).

\subsubsection{Fibre materials}

Copy paper, newsprint, cardboard and corrugated cardboard are all made from wooden fibre pulp. The pulp is produced from wooden materials by applying kraft, sulphite, mechanical or chemicalmechanical pulping methods (IPPC, 2001). The production of paper requires substantial amounts of water and energy. Copy paper consists of wood fibres, and it is used for writing and printing. The lignin that occurs naturally in the raw material is removed through chemical pulping to produce copy paper. Newsprint is used for newspapers and advertisement inserts and has a lower quality requirement compared to copy paper. It is produced from mechanical pulp, which means that the lignin is not removed. Cardboard, sometimes referred to as linerboard or container board, is used, for example, for hardback book covers and food packaging. Corrugated cardboard, also known as kraftliner or testliner (recycled materials), is used for boxes and containers for shipping. This type of fibre-based material is often a mixture of primary and secondary fibres.

Paper recycling is done by mechanically or chemical-mechanically pulping the paper (IPPC, 2001), a process which results in shortening the fibres and a subsequent reduction in strength. Mixing recycled paper with primary material is often required to meet paper strength specifications (Christensen \& Damgaard, 2010a).

\subsubsection{Glass}


Soda-lime glass, lead crystal and crystal glass are produced globally in the largest amounts (IPPC, 2013). Container glass for food and beverages is made of soda-lime glass and constitutes $50-60 \%$ of the total amount of glass produced globally (IPPC, 2001), as well as a much larger percentage of the non-durable glass that becomes waste after a single use. Glass, which is produced at $1500-1600^{\circ} \mathrm{C}$, can be found in clear, green or brown finishes. Clear glass is produced from quartz sand with low amounts of iron oxides, whereas manganese, iron, nickel and cobalt oxides are added to the production of brown glass, and chromium, cobalt and vanadium oxides are added to green glass (Christensen \& Damgaard, 2010b).

The removal of foreign objects, sorting by colour, size reduction and cleaning are the main steps involved in pre-treating glass before recycling, although some uses (e.g. as a drainage material) allow for the input of mixed colours (Christensen \& Damgaard, 2010b).

\subsubsection{Plastics}

Plastics can be classified as thermoplastics and thermosets. Examples of thermoplastics are polyethylene (PE), polyethylene terephthalate (PET), polyvinylchloride (PVC), polypropylene (PP), polystyrene (PS) and expanded polystyrene (EPS). Examples of thermosets are epoxide (EP), phenol-formaldehyde (PF), and polyurethane (PUR). Thermoplastics can be shaped by heating and will maintain their shape after cooling, whereas the melting point of thermosets is high enough that they will burn before they melt, which makes them hard to recycle (Christensen and Fruergaard, 2010). The aforementioned plastics are derived from crude oil through the distillation of naphtha. Some plastics may also be produced from natural gas by cracking it into ethylene. Additional monomeric chemicals are added, depending on the type of plastic produced (Plastic Europe, 2005).

Polystyrenes are divided into four types: polystyrene (PS), general purpose polystyrene (GPPS), high impact polystyrene (HIPS) and expandable polystyrene (EPS). The datasets presenting PS are generic, since the specific type was not specified further. The four types of PS are all produced with styrene as an input, but EPS also includes pentane. The production of GPPS and HIPS involves the input of butadiene.

Plastic recycling can be done either by feedstock recycling or mechanical recycling. Feedstock recycling breaks down the plastic to monomers, which can then be used in refineries and chemical production. Mechanical recycling includes shredding, cleaning, melting or granulation (Christensen and Fruergaard, 2010), and it produces quality products only when the materials are void of contaminants, sorted into a single type of polymer and sufficiently segregated according to the colour required for end use. For example, when containers are recycled in black plastics, sorting by colour is not important.

\subsubsection{Steel}

The major technologies used for the production of steel are electro ovens and oxygen blast furnaces. These technologies produce the same type of product but use different levels of energy consumption and therefore different emissions. Electric arc furnaces convert iron and steel scrap into steel by 
heating the materials with a high-power electric arc. In a basic oxygen furnace, oxygen is injected over molten iron (Worldsteel, 2012), while alloyed steel is iron mixed with other metals (e.g. chromium, nickel and tin) to enhance and customise the properties of the steel.

Steel scrap recycling is carried out in either an electric arc furnace or a basic oxygen furnace. An electric arc furnace can receive $100 \%$ scrap metals, while in the basic oxygen furnace scrap is limited to $25-30 \%$ of the total amount of metal (Damgaard and Christensen, 2010). Given the dominance of two technologies with different emission characteristics, an LCA should typically use a weighted average of emissions. Globally, it is estimated that the majority of post-consumer scrap is processed in electric arc furnaces (IISI, 2005), so this can be considered the representative technology in most cases.

\subsubsection{Aluminum}

The mining of bauxite, as well as alumina oxide refining, are the first steps in aluminum production, following which anode production, alumina smelting via electrolysis and finally refining take place (Aluminum Association, 2010). Alumina smelting and anode production consume large amounts of electricity, and they are possibly very $\mathrm{CO}_{2}$-intensive.

Waste aluminum cans are shredded, ferrous metals are sorted out and the aluminum is de-coated before melting and mixed with primary aluminum (Aluminum Association, 2010). Other types of waste aluminum do not need de-coating, and the rest of remanufacturing process is the same as for the cans (Aluminum Association, 2010).

\section{Results}

Table 2 presents minimum and maximum values in terms of $\mathrm{CO}_{2}$-equivalent per kg of material. The mean, standard deviation and number of datasets are also presented. In total, 366 datasets were evaluated, 270 of which represented primary production and 96 secondary production. Information on the data found for the primary and secondary production for each material is discussed in this section.

Figures 1-14 present $\mathrm{CO}_{2}$ emissions from the primary and secondary production of the 14 materials studied. The name of each dataset, as shown in Figures 1-14, shows the data source by reference to the numbers in Table 1. The year of the data collection is also presented, where available. The data represent different geographical areas - some are for a specific country (Switzerland, Germany, Sweden, etc.) while other datasets represent larger regions such as Europe or the USA. A few represent a global average. As noted in the figures, several datasets did not include geographical relevance.

To use LCI data properly in a specific study, it is important to identify from the background information which process is actually represented. The purpose of Figure 1-14, however, is primarily to illustrate significant differences in emissions which will dramatically affect the results of an LCA involving the recycling of materials. To put these data in context, estimates of emissions associated with other waste management activities are presented, namely collection (47-57 kg CO CO$_{2}$-eq/tonne (Eisted et al., 2009), separation in sorting 
plants (11 kg CO 2 -eq/tonne (Fitzgerald et al., 2012), landfilling in an average U.S. site (26 kg CO 2 -eq/tonne

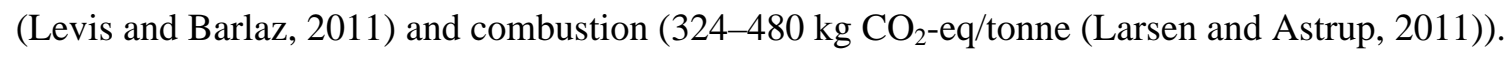

Table 2: Intervals for the primary and secondary production of materials and the number of datasets included in the study.

\begin{tabular}{|c|c|c|c|c|c|c|}
\hline \multirow[t]{2}{*}{$\begin{array}{l}\text { Primary/Secondary } \\
\text { production }\end{array}$} & \multirow[t]{2}{*}{ Material } & $\begin{array}{l}\text { Lowest } \\
\text { value }\end{array}$ & $\begin{array}{c}\text { Highest } \\
\text { value }\end{array}$ & Mean & $\begin{array}{l}\text { Standard } \\
\text { deviation }\end{array}$ & \multirow[t]{2}{*}{$\begin{array}{c}\text { Number of } \\
\text { datasets }\end{array}$} \\
\hline & & \multicolumn{4}{|c|}{$\mathrm{kg} \mathrm{CO}_{2} / \mathrm{kg}$ of material } & \\
\hline Primary & Copy paper & 0.04 & 4.08 & 1.24 & 1.02 & 26 \\
\hline Secondary & Copy paper & 0.38 & 1.56 & 0.73 & 0.41 & 11 \\
\hline Primary & Newsprint & 1.29 & 3.08 & 2.22 & 0.65 & 6 \\
\hline Secondary & Newsprint & 0.22 & 1.86 & 0.89 & 0.60 & 12 \\
\hline Primary & Cardboard & 0.70 & 3.89 & 1.85 & 0.99 & 8 \\
\hline Secondary & Cardboard & 0.61 & 0.61 & - & - & 1 \\
\hline Primary & $\begin{array}{l}\text { Corrugated card- } \\
\text { board }\end{array}$ & 0.49 & 2.46 & 1.14 & 0.45 & 17 \\
\hline Secondary & $\begin{array}{l}\text { Corrugated card- } \\
\text { board }\end{array}$ & 0.31 & 1.26 & 0.82 & 0.31 & 11 \\
\hline Primary & Glass & 0.24 & 1.10 & 0.74 & 0.20 & 24 \\
\hline Secondary & Glass & 0.07 & 0.86 & 0.46 & 0.26 & 8 \\
\hline Primary & Plastic HDPE & 0.70 & 3.10 & 1.88 & 0.68 & 14 \\
\hline Secondary & Plastic HDPE & 0.21 & 0.53 & 0.35 & 0.12 & 6 \\
\hline Primary & Plastic LDPE & 0.89 & 3.11 & 2.02 & 0.65 & 11 \\
\hline Secondary & Plastic LDPE & 0.19 & 0.89 & 0.45 & 0.31 & 4 \\
\hline Primary & Plastic LLDPE & 0.65 & 2.04 & 1.65 & 0.46 & 8 \\
\hline Secondary & Plastic LLDPE & - & - & - & - & 0 \\
\hline Primary & Plastic PET & 1.16 & 5.48 & 3.43 & 1.12 & 21 \\
\hline Secondary & Plastic PET & 0.11 & 1.10 & 0.53 & 0.31 & 7 \\
\hline Primary & Plastic PP & 1.14 & 4.44 & 2.41 & 1.01 & 12 \\
\hline Secondary & Plastic PP & - & - & - & - & 0 \\
\hline Primary & Plastic PVC & 0.92 & 4.07 & 2.41 & 0.69 & 30 \\
\hline Secondary & Plastic PVC & - & - & - & - & 0 \\
\hline Primary & Plastic PS & 1.39 & 4.36 & 2.99 & 0.65 & 24 \\
\hline Secondary & Plastic PS & 0.85 & 1.90 & 1.27 & 0.55 & 3 \\
\hline Primary & Steel & 0.40 & 7.03 & 2.21 & 1.34 & 41 \\
\hline Secondary & Steel & 0.02 & 2.94 & 1.27 & 1.02 & 11 \\
\hline Primary & Aluminum & 9.67 & 22.68 & 13.82 & 3.89 & 28 \\
\hline Secondary & Aluminum & 0.40 & 8.37 & 2.18 & 2.54 & 22 \\
\hline Datasets in total & & & & & & 366 \\
\hline
\end{tabular}

Fibre materials

Energy efficiency in the fibre production industry is reported to have improved considerably since 2000. One of the world's leading companies for paper and pulp production, Stora Enso, reports a 
decrease in electricity consumption of 6\% from 2007-2011 (Stora Enso, 2011). The branch organisation International Paper reports a decrease of 7\% in total energy used from 2007-2010 (IP, 2010) and the European Pulp and Paper Industry reports a decrease of $11.7 \%$ in specific primary energy used from 1991-2010 (CEPI, 2011). This might suggest that new datasets would show less $\mathrm{CO}_{2}$ emissions, but such a trend was not evident in the present study. There are two possible explanations for the lack of a trend. First, newer datasets may still be relying on old data and second, uncertainty in the data may be considerably greater than the maximum reported decrease in energy consumption.

For primary newsprint, American data show higher $\mathrm{CO}_{2}$ emissions per kilogram of primary and secondary newsprint than European data, due to the mix of energy sources used. Most datasets for paper production in Europe come from Sweden, where a major part of the energy mix is made up of hydropower and energy from biomass, which results in less fossil $\mathrm{CO}_{2}$ emissions than the average energy mix in Europe and USA. Note, however, that certain amounts of fibre produced in one country are undoubtedly consumed - and perhaps recycled - in another country. In addition, environmental impacts associated with hydropower electricity production do not currently take into account whether or not the flooding of land may have reduced the stock of forestry biomass, a vital source of $\mathrm{CO}_{2}$ uptake (Hertwich, 2013).

A few datasets used consequential system expansion, where it was considered that wood used for primary paper production could have been used for energy production. Therefore, the processes included natural gas for energy production instead of wood, since wood is used for primary paper production. This leads to higher $\mathrm{CO}_{2}$ emissions, since the other datasets do not include this additional use of natural gas. This kind of system expansion was included in datasets with names such as 'Incl. altern. use of fuel', and emissions were higher than for the other datasets. Whether or not such system expansion is appropriate is reliant on the specific study's objectives.

\subsubsection{Copy Paper}

Data presented for copy paper production were in the range of 0.04-4.08 $\mathrm{kg} \mathrm{CO}$-eq $/ \mathrm{kg}$ of material, taken from 26 datasets. The lowest emission of $0.04 \mathrm{~kg} \mathrm{CO}_{2}$-eq $/ \mathrm{kg}$ of material represents a European average production of copy paper, but it was not possible to find more information about the low emission in the GEMIS database. Only 11 datasets were found for secondary copy paper production, with a range of $0.38-1.56 \mathrm{~kg} \mathrm{CO}$-eq $/ \mathrm{kg}$ of material. Individual ranges were seen for each database for each material within this overall range. The mean for primary production was $1.24 \mathrm{~kg} \mathrm{CO}_{2}$ $\mathrm{eq} / \mathrm{kg}$ of material and the mean for secondary production was $0.73 \mathrm{~kg} \mathrm{CO}$-eq $/ \mathrm{kg}$ of material. One dataset for primary copy paper production was different from the others due to system expansion including an alternative use of fuel.

Data from GEMIS (source 14) were lower than other data presented for the production of copy paper. It was not possible to access documentation for the GEMIS processes due to obsolete links. Thus, the reason for the lower emission figures cannot be determined. 


\subsubsection{Newsprint}

Newsprint is used for newspapers and advertising inserts. Figure 2 shows the data obtained for the primary and secondary production of newsprint. Data found for the primary newsprint were in the range of $1.29-3.08 \mathrm{~kg} \mathrm{CO}$-eq/kg of material, whereas secondary production provided lower emissions in the range of $0.22-1.86 \mathrm{~kg} \mathrm{CO}$-eq $/ \mathrm{kg}$ of material. Six datasets were found for primary production and 12 for secondary production. Most of the datasets for the production of newspaper included a mix of primary and secondary paper, but this was not always clear from the name of the process, perhaps because many paper mills use a mixture of primary and secondary raw materials. Note that emission intervals for primary and secondary production overlapped, which highlights that it is crucial to choose representative data.

\subsubsection{Cardboard}

Emissions for primary cardboard were in the range of $0.70-3.89 \mathrm{~kg} \mathrm{CO}$-eq $/ \mathrm{kg}$ of material. Eight datasets were found for primary production, whereas only one dataset was found for secondary production, giving $0.61 \mathrm{~kg} \mathrm{CO}$-eq/kg of material (Figure 3).

The data from Avfall Norge were low compared to the other datasets shown in Figure 3. The reason for low emissions was not clear from the available background information. The Norwegian data were modelled in Simapro (PRé, 2013) and it was assumed that Avfall Norge uses the Norwegian energy mix, which consists mainly of hydropower and therefore leads to less $\mathrm{CO}_{2}$ emissions. The 'Virgin Cardboard, 1997' dataset from EASEWASTE, originated in Finland, also had relatively low emissions. The dataset provider used a Swedish energy mix, which includes significant use of nuclear and hydropower, with subsequent low greenhouse gas electricity intensity ( $\left.\mathrm{kg} \mathrm{CO}_{2} / \mathrm{kwh}\right)$.

\subsubsection{Corrugated cardboard/liner}

Data for corrugated cardboard are presented in Figure 4. The production of primary corrugated cardboard showed emissions ranging from $0.49-2.46 \mathrm{~kg} \mathrm{CO}$-eq/kg of material for 17 datasets. Secondary corrugated cardboard emissions were in the range $0.31-1.26 \mathrm{~kg} \mathrm{CO}$-eq $/ \mathrm{kg}$ of material from 11 datasets. As for copy paper, it was not possible to acquire outlier documentation from the GEMIS database (source 14).

The 'Kraft paper, bleached, at plant' dataset from Ecoinvent (source 7) included the infrastructure of the paper mill, energy production on-site and internal waste water treatment, items that were not included in other datasets. This is why the Ecoinvent data reside at the upper end of the range.

Another outlier is 'Kraft bleached' from 1995, taken from the Franklin database (source 13). In this dataset most of the energy comes from industrial burners inputting several types of fuel (coal, residual fuel oil and natural gas). This leads to higher $\mathrm{CO}_{2}$ emissions than the other datasets presented. 


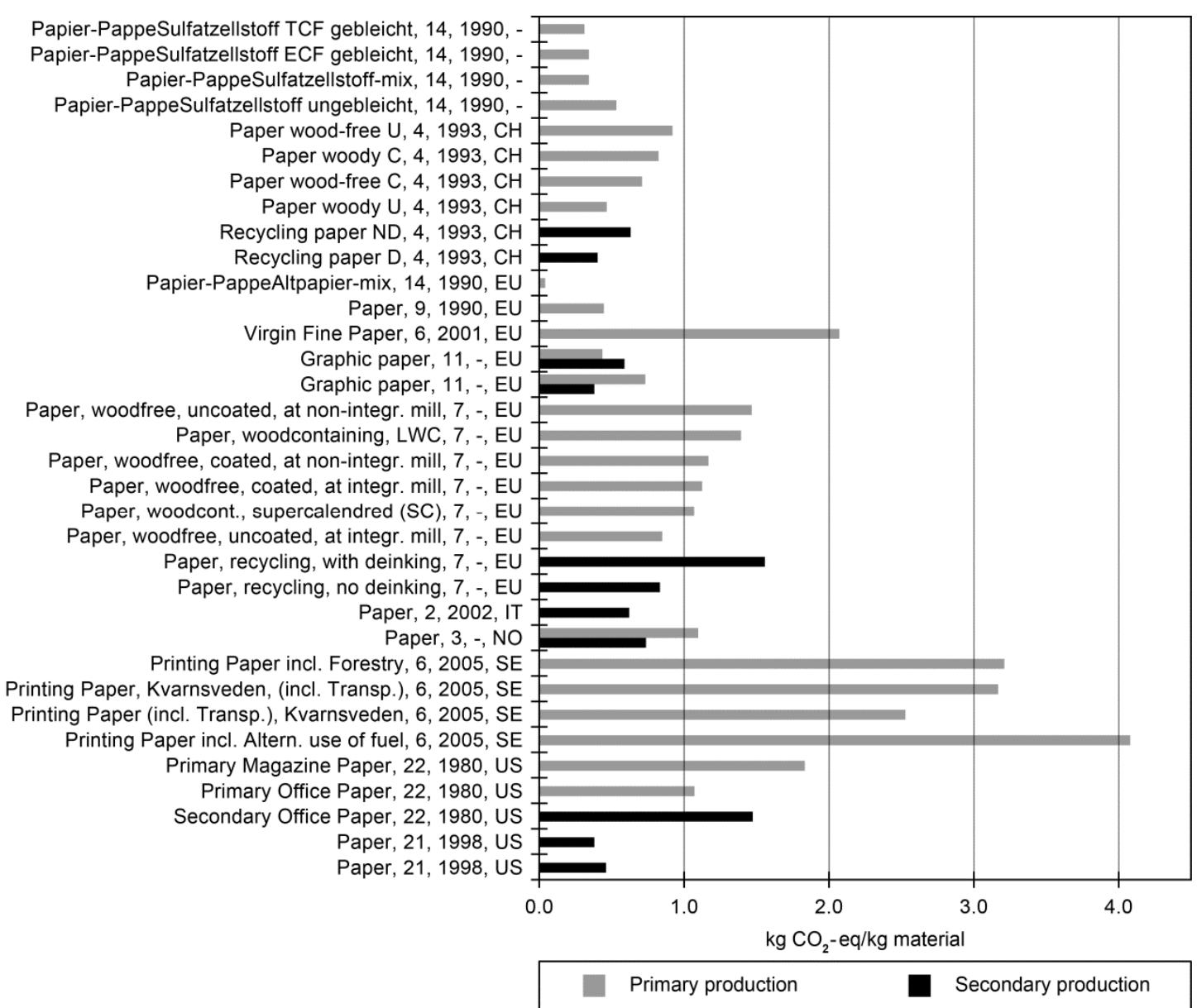

Figure 1: $\mathrm{CO}_{2}$-eq emissions from the primary and secondary production of copy paper. Numbers in names refer to sources in Table 1. “-”: No data found.

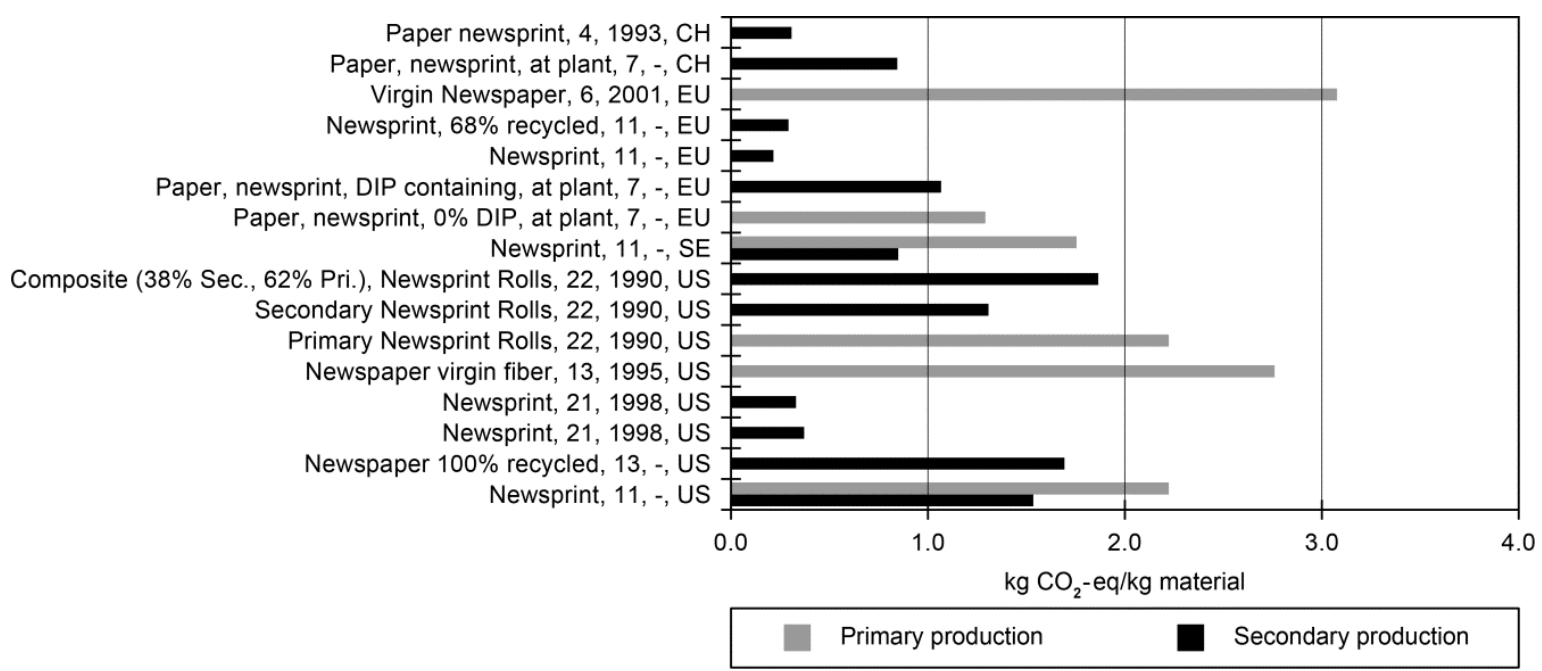

Figure 2: $\mathrm{CO}_{2}$-eq emissions from the primary and secondary production of newsprint. Numbers in names refer to sources in Table 1. “-”: No data found. 


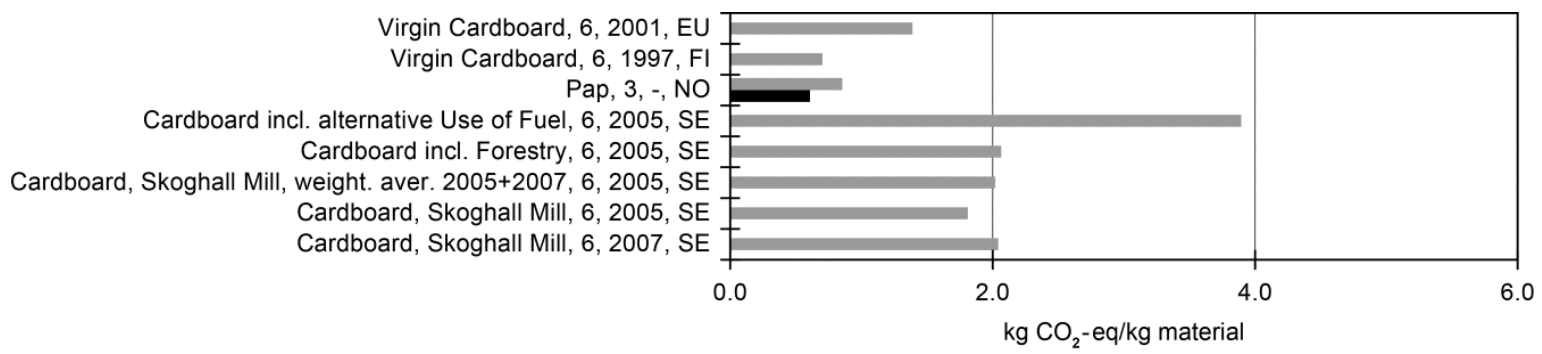

Primary production

Secondary production

Figure 3: $\mathrm{CO}_{2}$-eq emissions from the primary and secondary production of cardboard. Numbers in names refer to sources in Table 1. “-”: No data found.

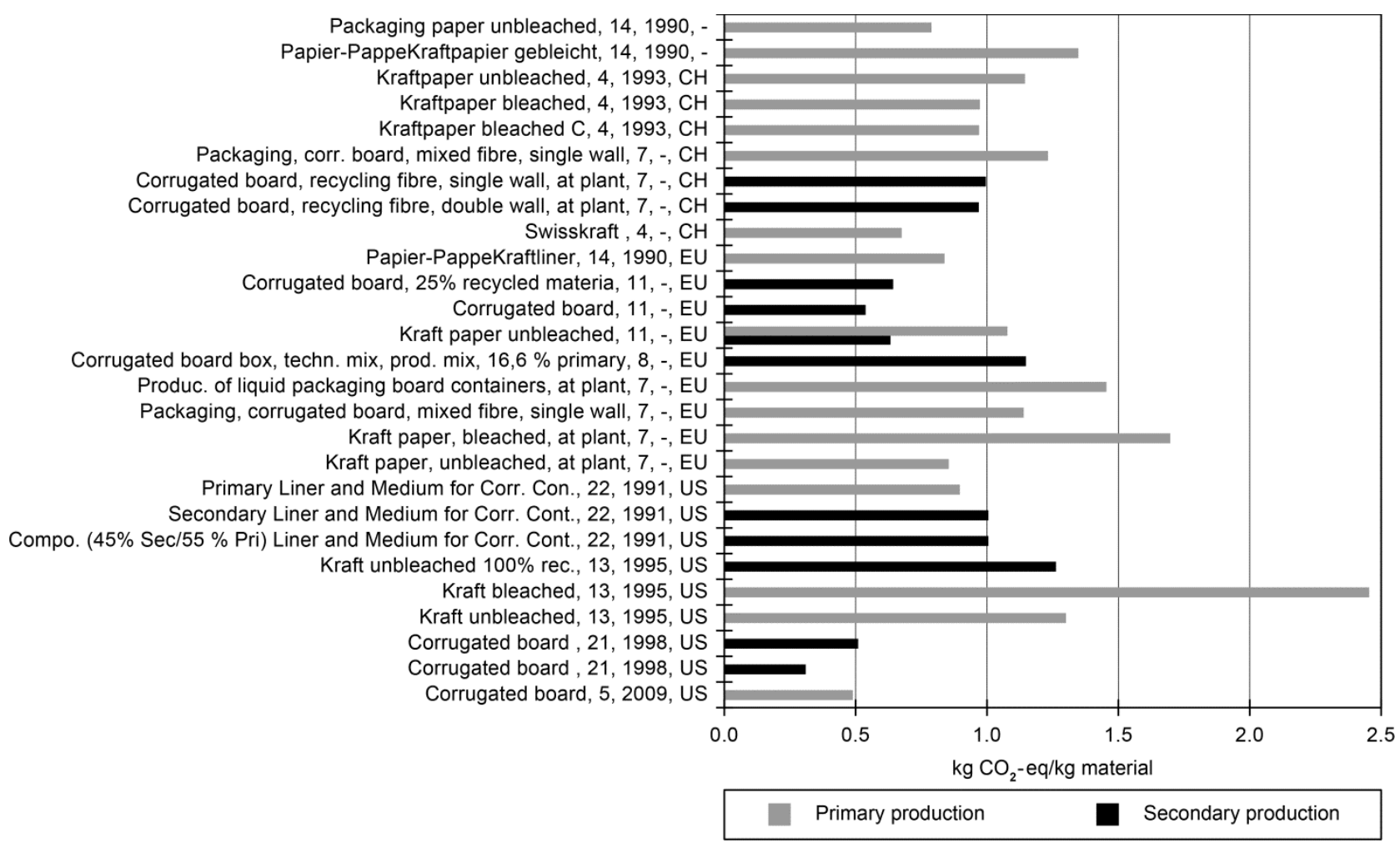

Figure 4: $\mathrm{CO}_{2}$-eq emissions from the primary and secondary production of corrugated cardboard. Numbers in names refer to sources in Table 1. “-”: No data found.

\subsection{Glass}

Emissions from the production of primary and secondary glass are presented in Figure 5. Datasets for specific colours as well as generic datasets are presented. Primary glass led to emissions of 0.24$1.1 \mathrm{~kg} \mathrm{CO} \mathrm{CO}_{2}$-eq $/ \mathrm{kg}$ of material and secondary glass gave emissions of $0.07-0.86 \mathrm{~kg} \mathrm{CO}_{2}$-eq/kg of material. The average values for glass production were not considerably different. The mean showed lower emissions for secondary $(0.46 \mathrm{~kg} \mathrm{CO}$-eq/kg of material) than for the primary (0.74 $\mathrm{kg} \mathrm{CO}_{2}-\mathrm{eq} / \mathrm{kg}$ of material) production. Eight datasets were identified for secondary production whereas 24 datasets were found for primary production. The small difference between primary and secondary production suggests that long distance transport of glass prior to recycling may eliminate 
the environmental benefits of recycling. Roughly, transport in large trucks results in emissions of 0.091-0.19 kg CO 2 -eq/tonne· km (Eisted et al., 2009).

The dataset "Glass - green (primary, 100\%)" from the EASEWASTE database does not include any available background information besides a reference number to the EDIP database (Wenzel et al., 1997) and it was not possible to find a reason for the low $\mathrm{CO}_{2}$ emission compared to the other data presented. It is included here to show the problems with lack of background information.

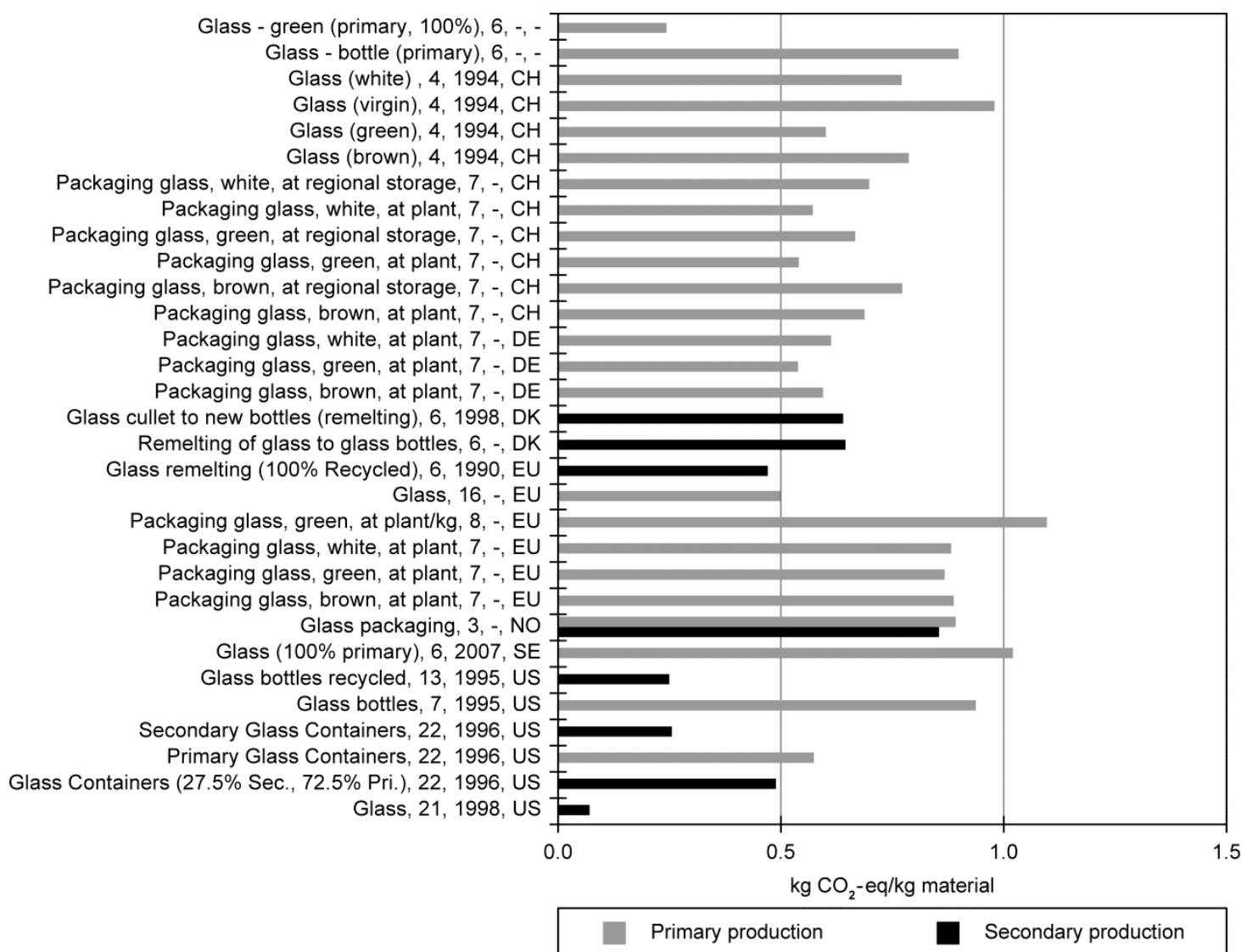

Figure 5: $\mathrm{CO}_{2}$-eq emissions from the primary and secondary production of glass. Numbers in names refer to sources in Table 1. “-”: No data found.

\subsection{Plastics}

Most data for the primary production of HDPE was found as granulate and resin but some datasets do not state the form/type of the material. The emissions from the production of the three types of PE (HDPE, LDPE and LLDPE) are on average similar for the primary production: $1.65-2.02 \mathrm{~kg}$ $\mathrm{CO}_{2}$-eq/kg of materials (Figures 6-8). The differences between the primary and the secondary mean values for the HDPE, LDPE and PET were 81\%, 78\%, 84\% respectively; suggesting that recycling is beneficial with respect to the emission of $\mathrm{CO}_{2}$. 
For HDPE, LDPE and LLDPE the IDEMAT database (source 15) gives lower emission. The dataset is very simple and only includes natural resources and emissions, but it was not possible to find the background information, since the background report is no longer available.

Data from the databases "Industry data 2.0", "Ecoinvent” and "ELCD” are all based on data from Plastic Europe and the data from these three databases are equal (Figure 8).

The 21 dataset for primary PET showed emissions from 1.16-5.48 kg CO 2 -eq/kg of material (Figure 9). In total 7 datasets for production of secondary PET gave emissions in the range $0.11-1.1 \mathrm{~kg}$ $\mathrm{CO}_{2}$-eq $/ \mathrm{kg}$ of material.

Data presented in Figure 10 for primary PP production were in the range of 1.14-4.44 kg CO -eq $/ \mathrm{kg}$ of PP produced. No data were identified for secondary PP production. Two datasets from Source 20 represented the further processing of resin/granulate of PP to PP film and these gave higher $\mathrm{CO}_{2}$ emissions than the other dataset due to higher energy consumption.

The PVC data showed emissions from $0.92-4.07 \mathrm{~kg} \mathrm{CO}$-eq $/ \mathrm{kg}$ of material for primary production, with a mean of $2.41 \mathrm{~kg} \mathrm{CO}$-eq/kg of material (Figure 11). No secondary data were identified. The highest emission was from the ETH-ESU 96 'PVC high impact' process. The ETH-ESU 96 database is no longer included as a Simapro database due to obsolescence, but it could still be used from earlier acquisitions. Data from Industry 2.0 (source 17) are provided to Simapro by Plastic Europe (source 20). Despite differences in the ages of the datasets, LCIs are similar.

The $\mathrm{CO}_{2}$ emissions found in different databases, as presented in Figure 12, are within the range of 1.39-4.36 kg CO 2 -eq $/ \mathrm{kg}$ of plastic produced. Three datasets were found for the secondary production of PS with emissions of $0.85-1.90 \mathrm{~kg} \mathrm{CO}$-eq $/ \mathrm{kg}$ of secondary PS.

Lower $\mathrm{CO}_{2}$ emissions were reported for all types of plastics from the US LCI database (Source 23) compared to the European data from several sources. Data were set up in the US LCI database with 'dummy' processes, meaning that the user is expected to specify the energy mix that the processes use. The 'dummy' processes contained no data and represented, for example, $1 \mathrm{kWh}$. In the main dataset the process was called 'Dummy_Electricity, at cogenerating unit, unspecified/US', and the process used $0.22 \mathrm{kWh}$. Tools (e.g. Simapro) including US LCI data did not change the setup of the data, and the empty 'dummy' processes were therefore still included in the data, meaning that no emissions were attributed to electrical energy requirement. In addition, some transport processes were included in these datasets as empty 'dummy' processes. Therefore, the American data for plastics seem incomplete and they cannot be compared to other datasets. Data are shown here to provide an example of the types of errors that occur in databases. 


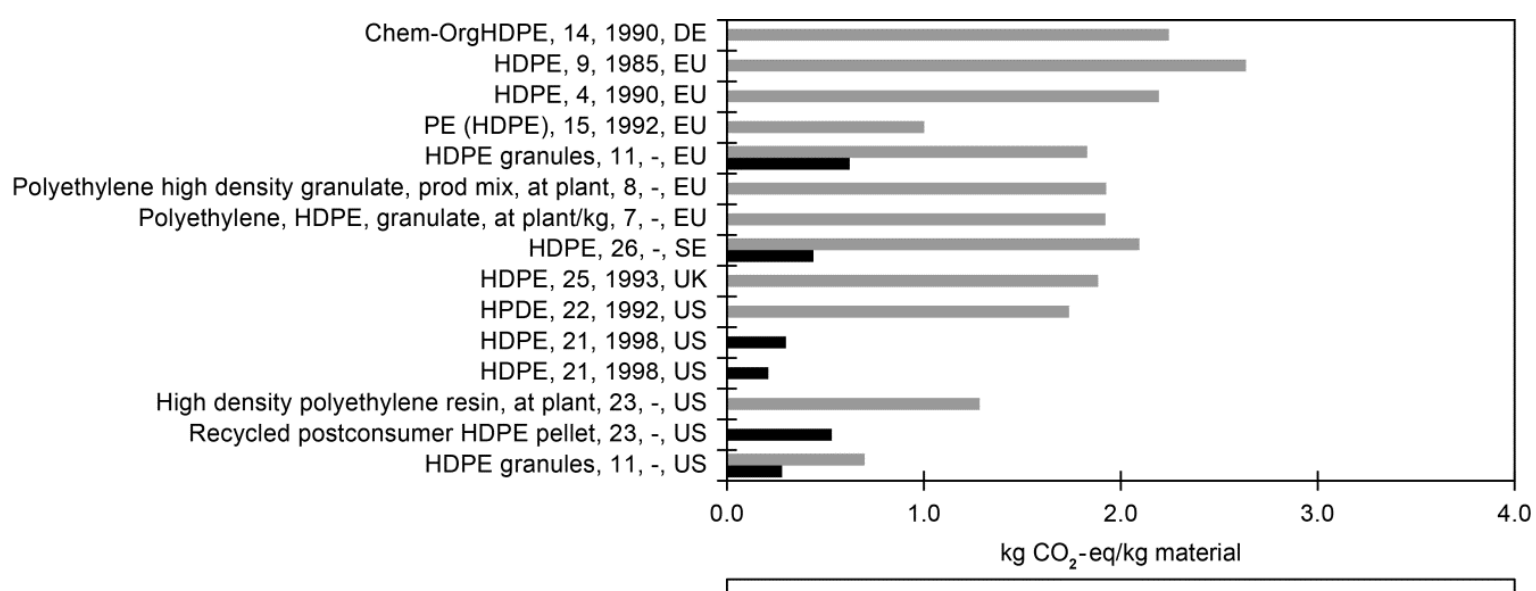

Primary production $\square$ Secondary production

Figure 6: $\mathrm{CO}_{2}$-eq emissions from the primary and secondary production of high density polyethylene. Numbers in names refer to sources in Table 1. “-”: No data found.

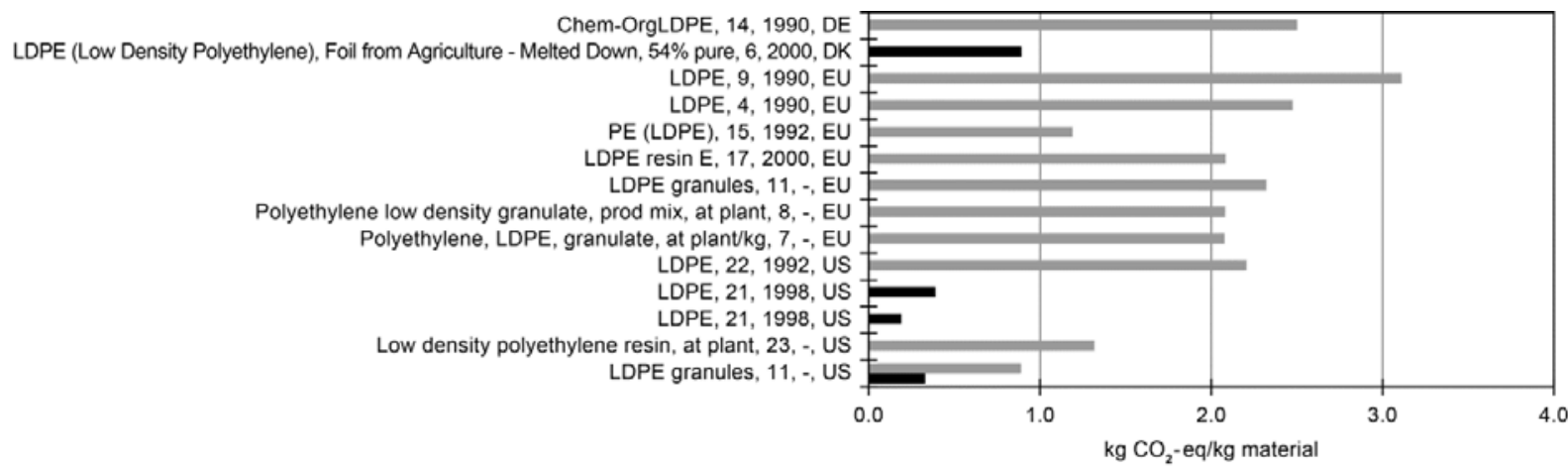

Primary production $\quad$ Secondary production

Figure 7: $\mathrm{CO}_{2}$-eq emissions from the primary and secondary production of low density polyethylene. Numbers in names refer to sources in Table 1. “-”: No data found.

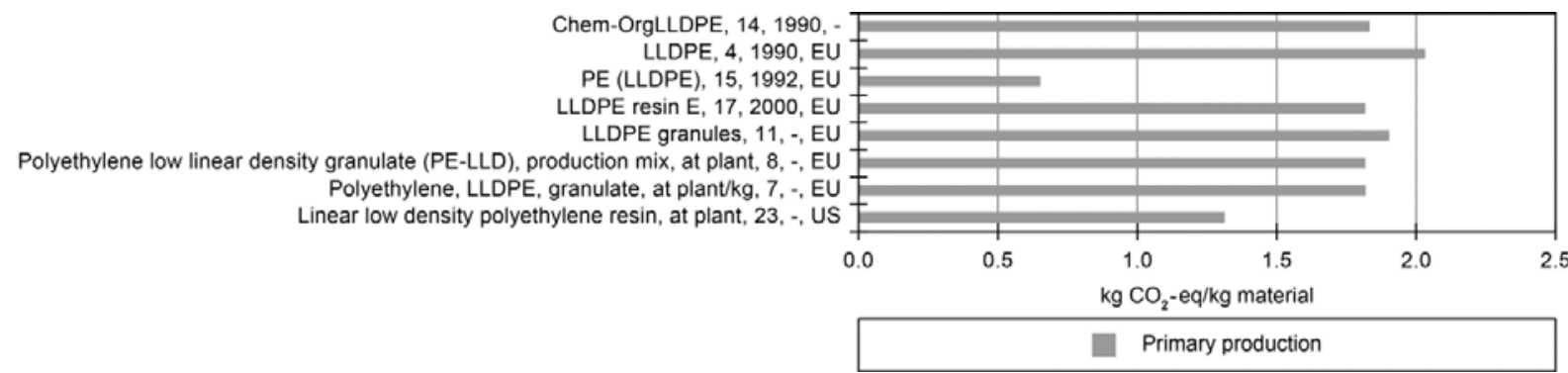

Figure 8: $\mathrm{CO}_{2}$-eq emissions from the primary production of linear low density polyethylene. Numbers in names refer to sources in Table 1. “-”: No data found. 


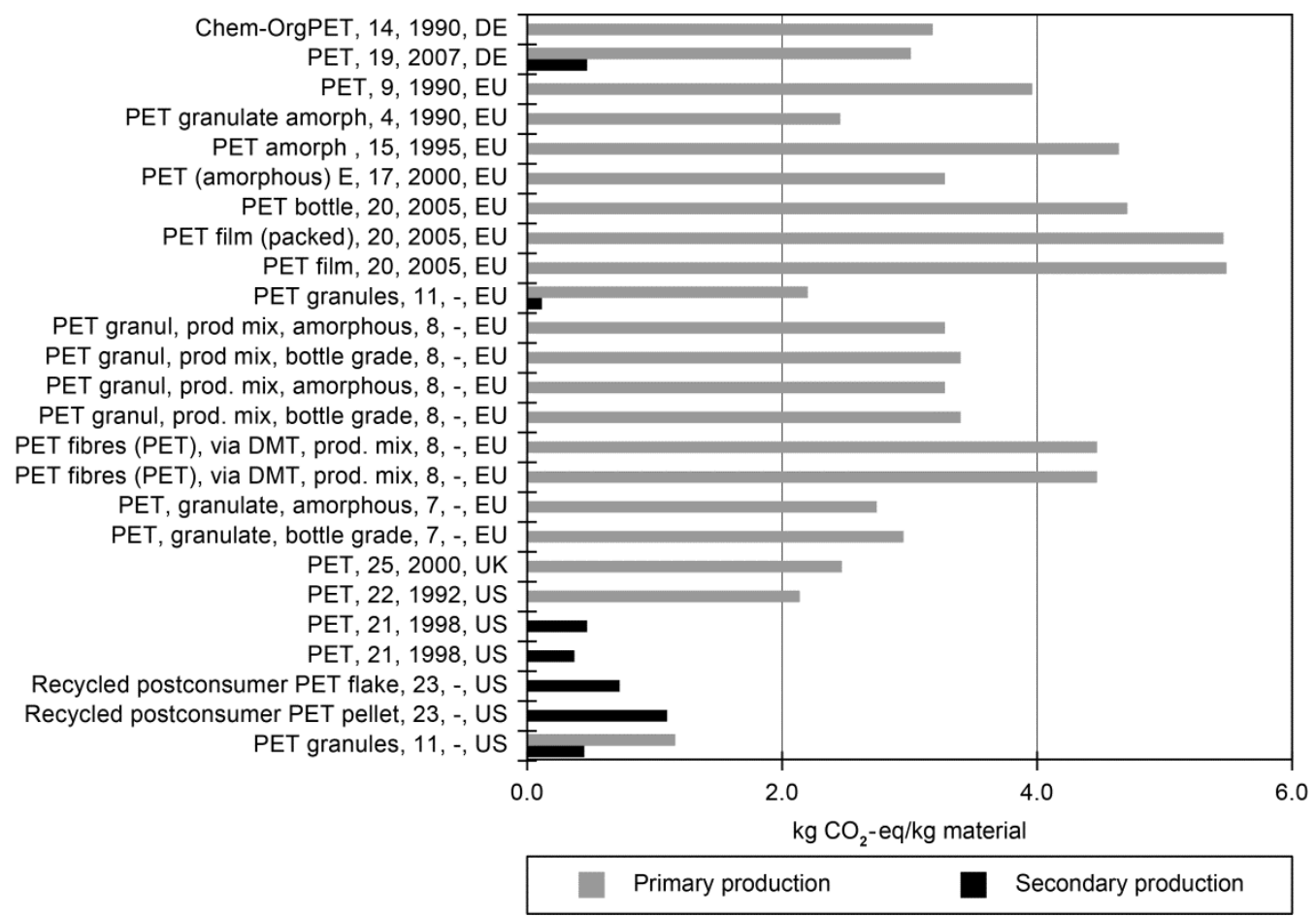

Figure 9: $\mathrm{CO}_{2}$-eq emissions from the primary and secondary production of polyethylene terephthalate. Numbers in names refer to sources in Table 1. “-”: No data found.

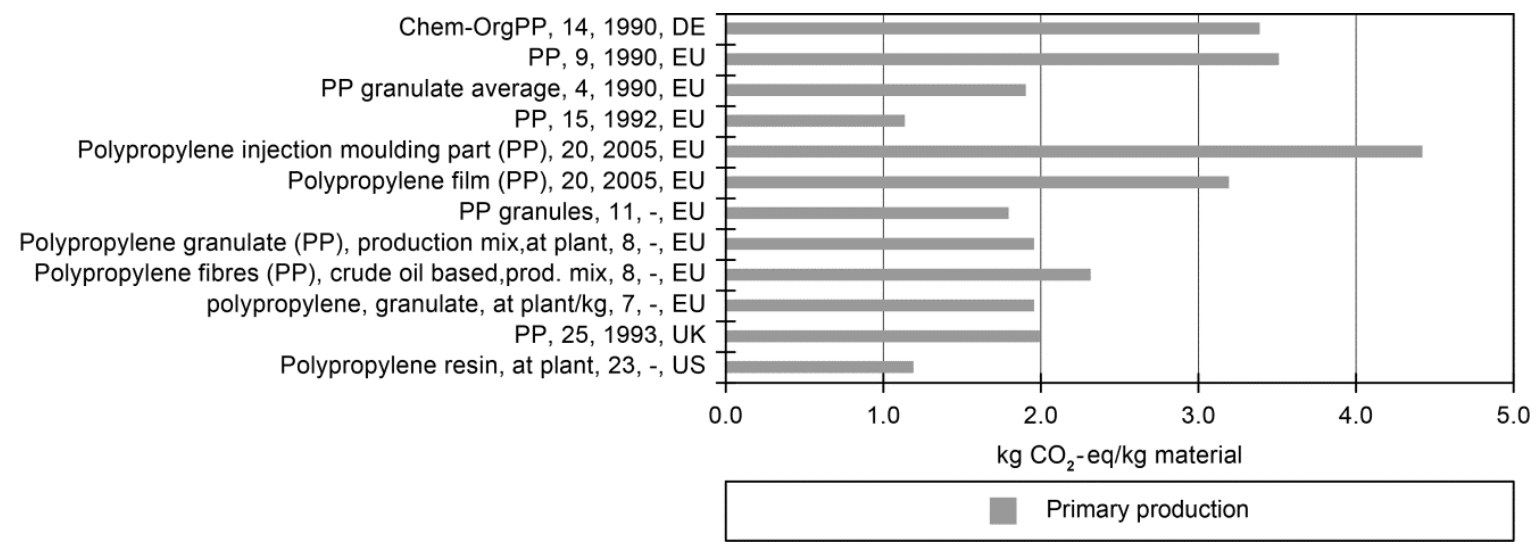

Figure 10: $\mathrm{CO}_{2}$-eq emissions from the primary production of polypropylene. Numbers in names refer to sources in Table 1. “-”: No data found. 


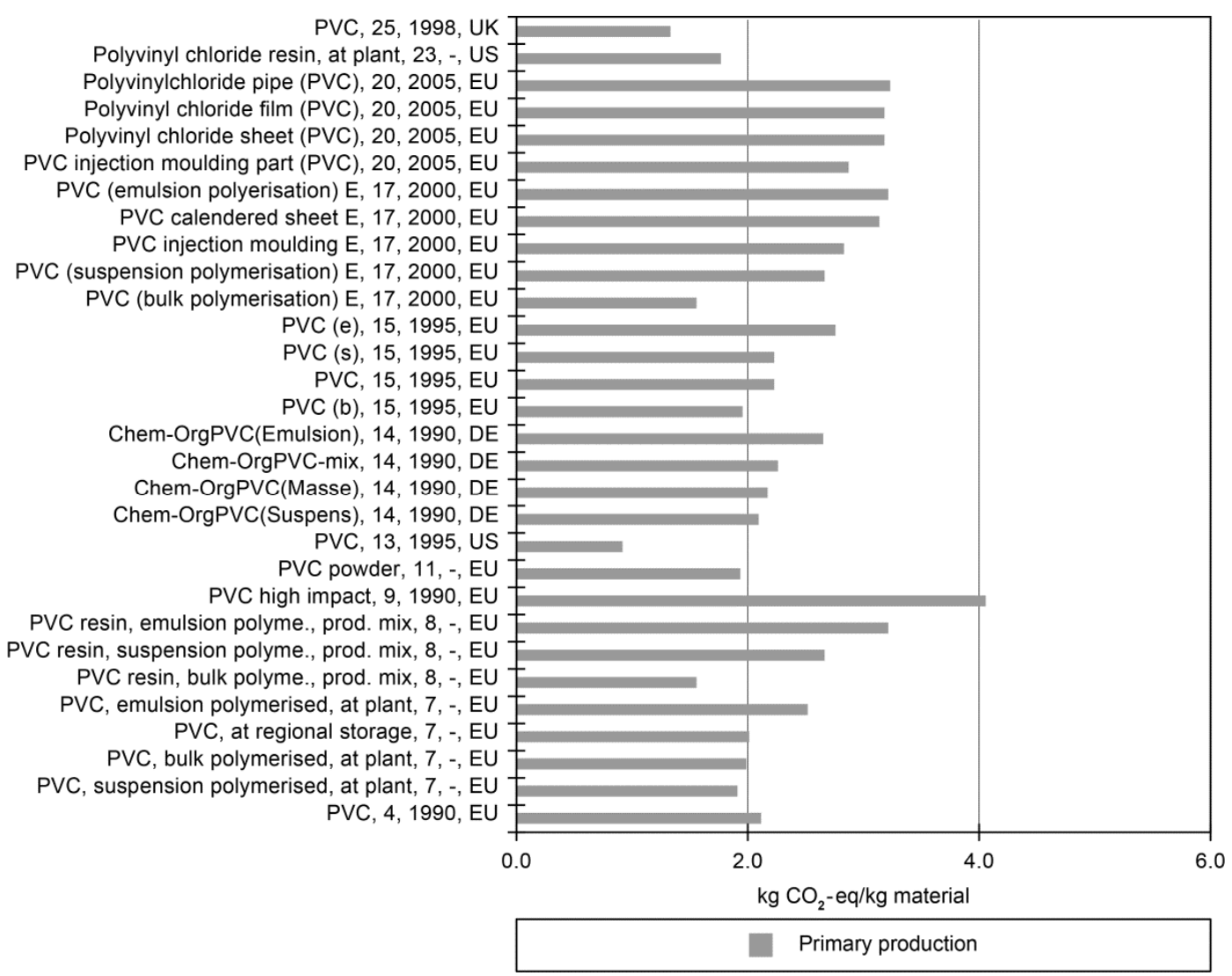

Figure 11: $\mathrm{CO}_{2}$-eq emissions from the primary production of polyvinyl chloride. Numbers in names refer to sources in Table 1. “-”: No data found.

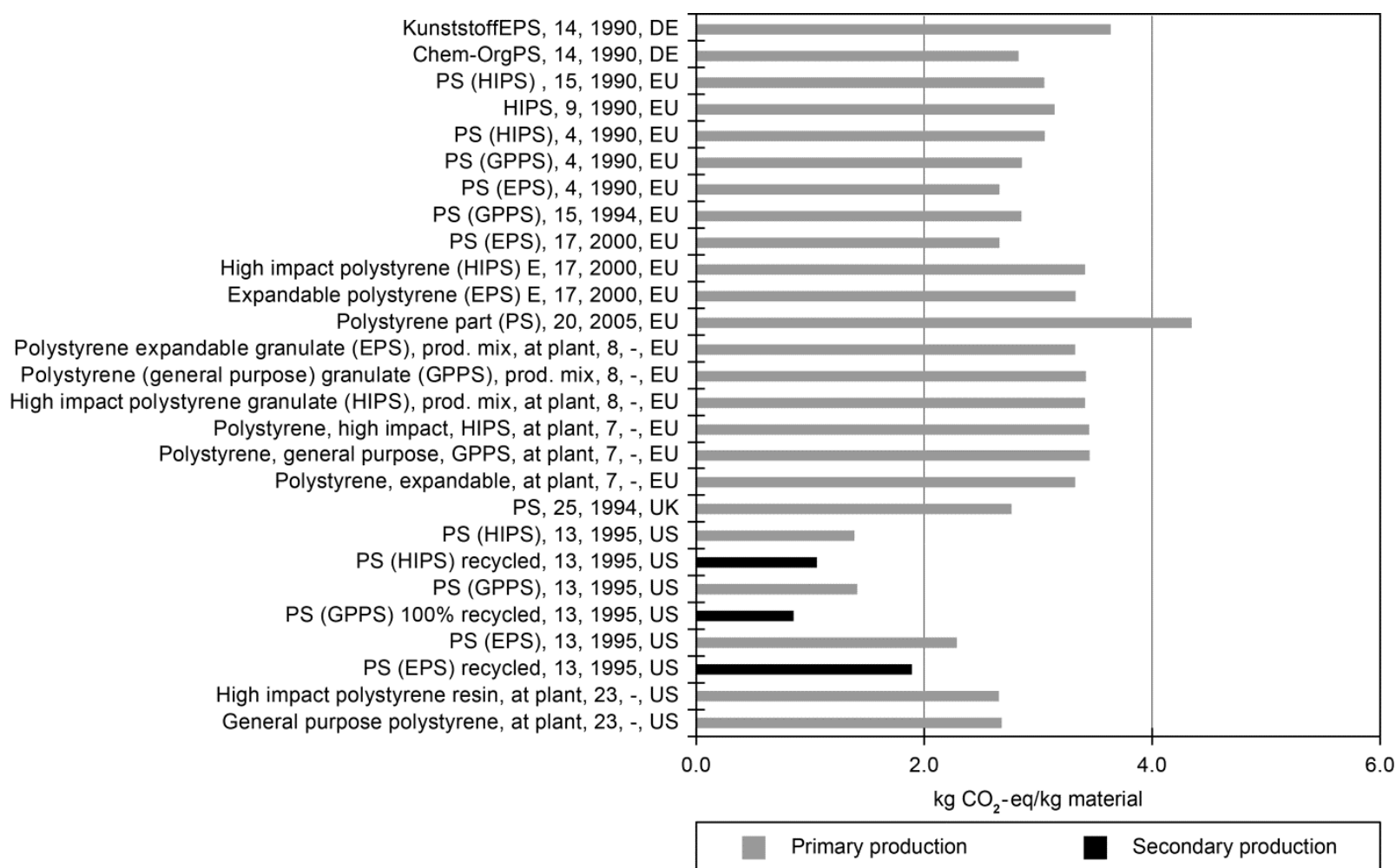

Figure 12: $\mathrm{CO}_{2}$-eq emissions from the primary and secondary production of polystyrene. Numbers in names refer to sources in Table 1. “_”: No data found. 


\subsection{Steel}

World Steel reports a decrease of 50\% in the energy consumption per tonne of crude steel produced in North America, Japan and Europe between 1975 and 2005 (World Steel Association, 2012). In the data presented in Figure 13, however, it was not possible to see such a trend over time. For primary steel production, 41 datasets were found and the variations were substantial (0.4-7.03 $\mathrm{kg} \mathrm{CO}_{2}$ eq/kg steel). The mean for primary steel was $2.21 \mathrm{~kg} \mathrm{CO}$-eq/kg of steel. Eleven datasets were found for secondary production, and these reported a range of $0.02-2.94 \mathrm{~kg} \mathrm{CO}$-eq/kg of steel with a mean of $1.3 \mathrm{~kg} \mathrm{CO}$-eq $/ \mathrm{kg}$ of steel.

No documentation was found for the GEMIS processes from Czechoslovakia and China, which have high emissions compared to the other datasets presented for steel. Low emissions in the German data from GEMIS were due to the fact that these included only primary steel processing and not mining processes.

The 'Steel (sec)' process from IDEMAT represents emissions from the electro furnace production of $100 \%$ secondary steel. The emissions appear high compared to the 'Secondary EAF steel' from US EPA datasets. It was not possible to find adequate background information from IDEMAT for the data. 


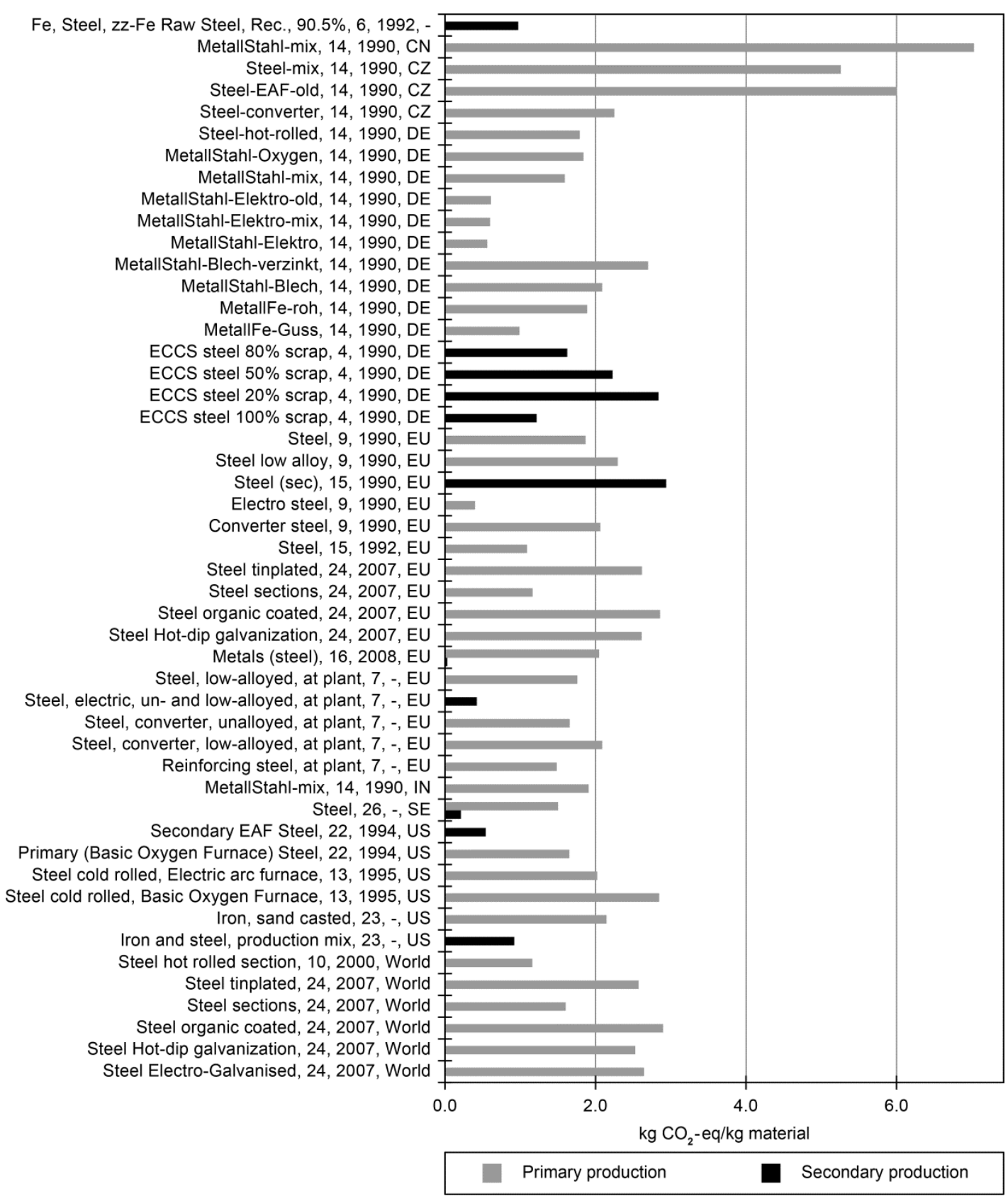

Figure 13: $\mathrm{CO}_{2}$-eq emissions from the primary and secondary production of steel. Numbers in names refer to sources in Table 1. “-”: No data found.

\subsection{Aluminum}

The global average electrical energy used per tonne of primary aluminum decreased by $10 \%$ from 1980 to 2005 (IEA, 2007; McMillan and Keoleian, 2009). Furthermore, the $\mathrm{CO}_{2}$ emissions caused by the production of primary aluminum decreased by $0.2-37 \%$ except for African production (increase of 46\%), where a change in energy production went from hydroelectricity to coal-fired production (McMillan and Keoleian, 2009). However, it was not possible to find LCI data to support these developments (Figure 14). For primary aluminum production, the numbers are equal for European data and American data, while differences between primary aluminum production and pri- 
mary aluminum goods (sheets, foil and cans) are not significant. This could be due to high energy consumption during the production of intermediate material, whereas the manufacturing of the good is less energy-intensive. Mean emissions for primary aluminum were $13.8 \mathrm{~kg} \mathrm{CO}$-eq/kg with a range of 9.7-22.7 $\mathrm{kg} \mathrm{CO}$-eq/ $/ \mathrm{kg}$. For secondary aluminum, the mean was $2.2 \mathrm{~kg} \mathrm{CO}$-eq/ $/ \mathrm{kg}$ with a range from $0.4-8.4 \mathrm{~kg} \mathrm{CO}$-eq $/ \mathrm{kg}$, thus documenting the significant advantage of recycling aluminum.

The process involved in producing aluminum is the same in all datasets taken from GEMIS (source 14), and only the energy source is different, depending on the country-specific mix. The dataset from Norway includes 99.5\% hydropower, whereas the Australian dataset includes $77.6 \%$ coal, $12.6 \%$ gas, $1.3 \%$ oil and the remaining sources as hydropower and waste, which causes the large variations between GEMIS datasets. 


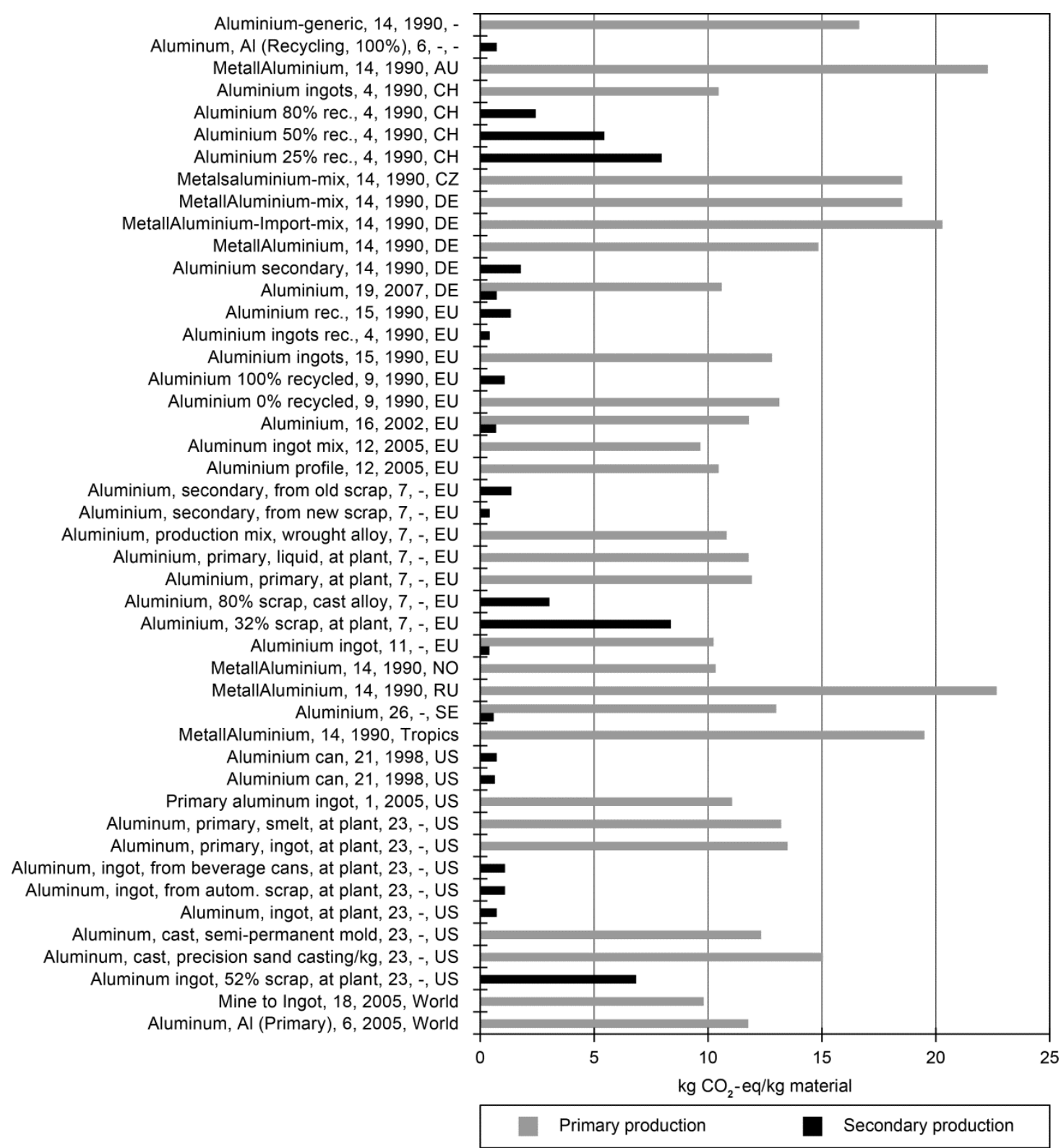

Figure 14: $\mathrm{CO}_{2}$-eq emissions from the primary and secondary production of aluminum. Numbers in names refer to sources in Table 1. “-”: No data found.

\section{Discussion}

Choosing inventory data for an LCA study is difficult, as it is not possible to evaluate data quality (e.g. on the basis of the pedigree matrix from Weidema and Wesnæs (1996)) and choose data when databases are not transparent and background information is scarce or not available. Some datasets appear to be equal, at least according to the name and short description, but the data are different. Large variations were shown for all materials in this study, as summarised in Figure 15.

The mean and standard deviations of the collected data are presented in Figure 15. From the means, it is clear that primary production produces higher emissions than secondary production, thus suggesting in a direct comparison that it is beneficial to recycle. Conversely, Figure 15 also shows the 
highest and lowest values, which suggests that it is possible to combine datasets in a way that the recycling of materials does not appear beneficial. Choosing the right dataset for an LCA is therefore very important, since this choice can dramatically affect the results.

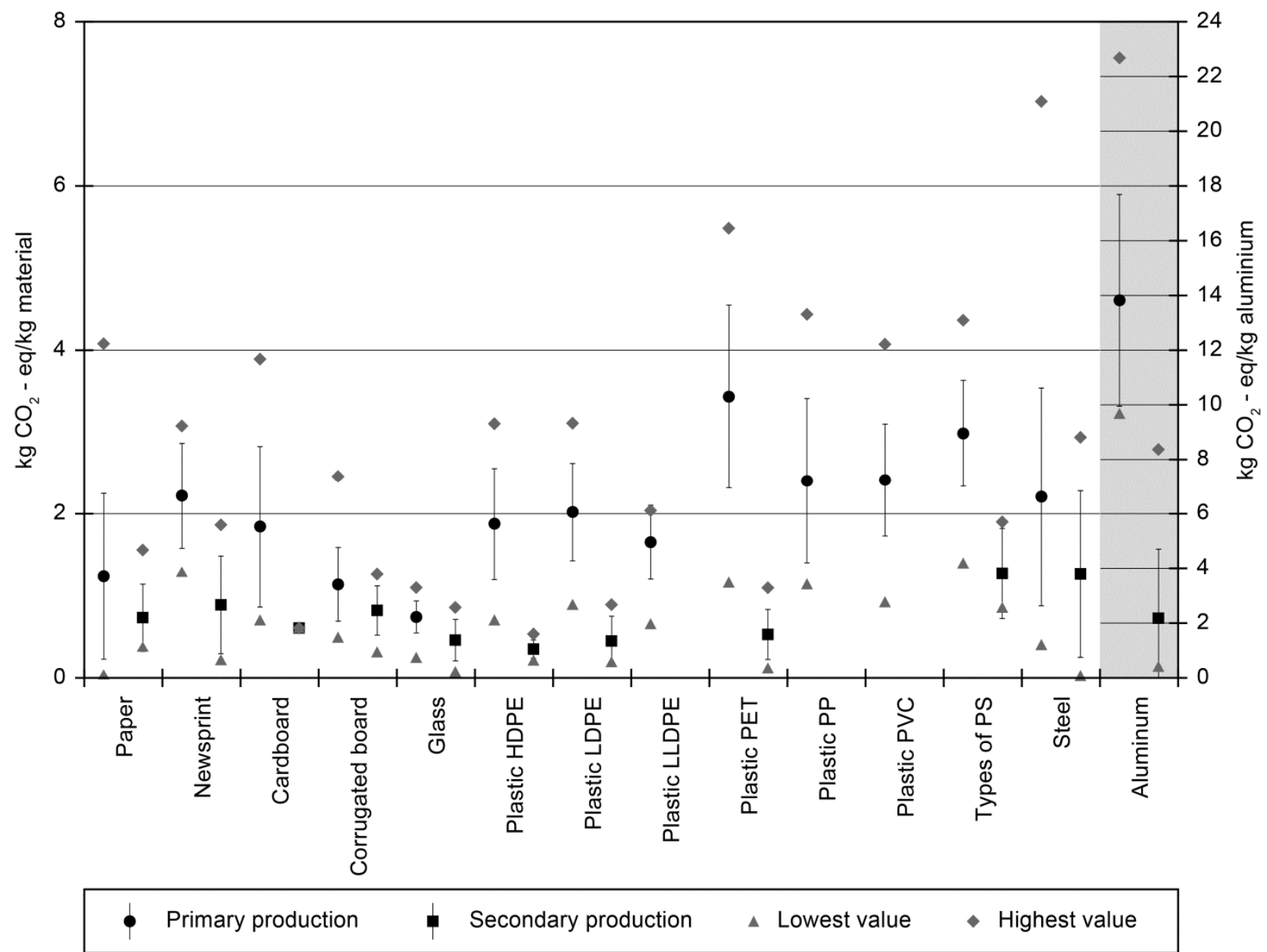

Figure 15: Highest and lowest values and mean values of all data found for each material and standard deviation. The grey colour highlights that aluminum has its own axis. No data were found for secondary LLDPE, $\mathrm{PP}$ and PVC.

A crucial parameter in the datasets is the provision of energy used, especially electricity, since the per kWh contribution varies considerably based on the type of fuel. As presented in the material sections above, datasets from countries with a high renewable energy input into the national grid had a very low environmental impact (i.e. Norway with 99\% renewable electricity, versus $91 \%$ coal in Poland (EEA, 2007)). If these datasets are to be used in other countries it is crucial that the user is aware of the importance of this anomaly and has the option to change the grid mix. A number of databases (e.g. GEMIS, Ecoinvent) provide country-specific datasets, where the grid mix is fitted to the country. However, for a number of the datasets, data were aggregated to a level where the user could not identify how large a share of the emissions was related to energy use. 
The option to change the energy grid is also crucial if carrying out a consequential LCA. Here the marginal electricity source plays a key role, and the user needs to be able to ensure the use of representative data. For example, McMillan and Keoleian (2009) showed how aluminum production in Europe is a lot less $\mathrm{CO}_{2}$-intensive in comparison to Asian production. McMillan and Keoleian (2009) also noted that the majority of growth in primary aluminum production was taking place in Asia, so avoided primary production should be based on Asian production data and not on European data. This could be done either by using Asian LCI data or by adopting the marginal energy carrier in these countries. In the latest version of Ecoinvent (v3) (2013), the database now directly offers users the option to use consequential LCIs with flexible energy grids.

The LCA practitioner assessing recycling systems may know the company receiving the materials in a specific case. This company can either recycle the material or export sorted quantities for recycling elsewhere. In the case of export, it is hard for the practitioner to know which data to use for the recycling process or for the substituted process. In many cases the secondary process is not known because secondary materials are traded worldwide, and most likely the substituted process is impossible to identify because the latter is a consequence of how the markets react when more products based on recovered material enter the global market. If data are available, combining different sets of data for secondary and primary production could give an indication of variations in the outcome of the overall material recycling, although it is difficult to judge how representative each combination is for a global market. As a minimum requirement, when primary and secondary manufacturing data are used in an LCA, it is essential to perform sensitivity analyses for exploring the impacts of data uncertainty (Clavreul et al., 2013).

ISO standards (ISO, 2006) describe how to prepare inventory data and how to make background information transparent. This study shows that the standard is seldom followed. Branch organisations, e.g. Plastic Europe, are preparing and publishing inventory data of good quality, which is possible because Plastic Europe has an interest in the quality of the data used in LCAs regarding their production. Data consensus on the subject of industrial production processes could provide good quality inventories and would certainly raise the quality of LCAs. The data should follow the ISO standard and include specified energy data and background information to make the data transparent. Finally, the data should be presented so that they may be disaggregated, for example so that alternate electricity grids can be used.

Providing LCI data in a database requires an awareness of maintenance, since data can become outdated as new technologies are introduced. Commercial databases have more resources available for updating datasets than their publicly available counterparts, and many datasets are available online for free, but these are often inadequate. Moreover, commercial databases may also include obsolete data if they are not maintained.

This study has described some of the challenges related to choosing data for LCA studies, but it is difficult to provide guidelines on which datasets to choose. The goal of this study was to highlight some of the challenges LCA modellers face as a result of large variations in available databases, 
and as such it highlights the need for any LCA to carry out a thorough sensitivity assessment, in order to ensure a robust assessment (Clavreul et al., 2013).

Finally, the data in this paper for secondary production represent recyclable materials received at the remanufacturing facility. Material losses occur between deposition into a recycling container and arrival at a remanufacturing facility. Data should therefore not be used to describe anything about the effect of recycling, but be used in a proper context by taking the whole waste management system into account.

\section{Summary and conclusions}

Inventory data used for LCAs vary in transparency, depending on energy systems and the quality of background information. Therefore, it is difficult for the LCA practitioner to choose the right datasets. A total of 366 datasets were included in this study, in order to gain an overview of the challenges confronting practitioners. The data collected represented 270 datasets for the primary production and 96 datasets for the secondary production of 14 materials. The materials assessed were copy paper, newsprint, cardboard and corrugated cardboard, plastics (HDPE, LDPE, LLDPE, PET, PP, PS and PVC), steel, glass and aluminum. The number of datasets for the recycling of materials was low, and for some materials critically low (e.g. some plastic types), while several datasets on the primary production of materials were present in existing databases. Large variations in $\mathrm{CO}_{2}$ emissions were observed among datasets representing the same material production. Variations within a factor of 3 to 5 were not uncommon, which could dramatically affect the results of an LCA involving material recycling. Although energy savings have been reported for many industries, a decreasing trend over time in $\mathrm{CO}_{2}$-emisisons per $\mathrm{kg}$ of material in the LCI datasets was not identified.

An inherent problem exists in combining datasets for recycling processes and for substituted primary production processes. Often they are only linked through the market, and by choosing datasets representing specific plants or technologies, it is difficult to accurately represent which recycling processes receiving secondary materials trade on the market for recyclables and which primary processes in the market will produce less goods as more recycled products reach a market. Identifying such relations requires perfect and dynamic market information. Even with this information, though, it is not clear how to incorporate shifts in manufacturing location over time in traditional LCAs.

ISO standard 14044 provides clear guideline on how to prepare LCI data. If these guidelines were followed and the quality of the background information was more precise than it is today, it would be easier to choose the right LCIs regarding material recycling.

Plastic Europe provides data for both public and commercial databases by contributing European primary production averages. If more industry associations and branch organisations provided data and included proper background information following the ISO standard, inventory data would be of higher quality, and better inventory data and documentation would make it easier for LCA practitioners to perform LCAs of improved quality. 


\section{References}

Aluminum Association. Life Cycle Impact Assessment of Aluminum Beverage Cans; 2010. Available from: http://www.container-recycling.org/assets/pdfs/aluminum/LCA-2010AluminumAssoc.pdf. [cited 02.11.13].

Arena U, Mastellone M L, Perugini F and Clift, R. Environmental assessment of paper waste management options by means of LCA methodology, Industrial and Engineering Chemistry Research 2004; 43 (18): 5702-5714.

Avfall Norge. Klimaregnskap for avfallshåndtering. Fase I: Glassemballasje, etallemballasje, papir, papp, plastemballasje og våtorganisk avfall; 2009. Available from:

http://ostfoldforskning.no/publikasjon/klimaregnskap-for-avfallshandtering-fase-i-og-ii-576.aspx [cited 02.11.13].

Brandão M, Levasseur A, Kirschbaum M U F., Weidema B P, Cowie A L, Jørgensen S V, Hauschild M Z. Key issues and options in accounting for carbon sequestration and temporary storage in life cycle assessment and carbon footprinting. The International Journal of Life Cycle Assessment, 2012; 18 (1), 230-240.

BUWAL. Bundesamt für Umwelt, Wald und Landschaft (BUWAL); 1990. Available from: http://www.bafu.admin.ch/index.html?lang=en , Access to data through www.ecoinvent.org [cited 02.11.13].

CEPI - Confederation of European Paper Industries. Key statistics 2011; 2011. http://www.cepi.org/ [cited 02.11.13]

Christensen T H, Damgaard A. Recycling of Paper and Cardboard. In: Christensen T H. Solid Waste Technology \& Management, Volume 1 \& 2, John Wiley \& Sons, Ltd., Chichester, UK; 2010a p. 203-210 doi: 10.1002/9780470666883.ch15

Christensen T H, Damgaard A. Recycling of Glass. In: Christensen T H. Solid Waste Technology \& Management, Volume 1 \& 2, John Wiley \& Sons, Ltd., Chichester, UK.; 2010b p. 211-219. doi: 10.1002/9780470666883.ch16

Christensen T H, Gentil E, Boldrin A, Larsen A W, Weidema B P, Hauschild M Z. C balance, carbon dioxide emissions and global warming potentials in LCA-modelling of waste management systems. Waste Management \& Research 2009; 27 (8): 707-15.

Christensen, T H and Fruergaard, T. Recycling of Plastic. In: Christensen T H. Solid Waste Technology \& Management, Volume 1 \& 2, John Wiley \& Sons, Ltd., Chichester, UK; 2010 p.220-233. doi: 10.1002/9780470666883.ch17

Clavreul J, Baumeister H, Christensen T H, Damgaard A. EASETECH - an Environmental Assessment System for Environmental TECHnologies. Under review: Environmental Modelling \& Software; 2014. 
Clavreul J, Guyonnet D, Tonini D, Christensen T H. Stochastic and epistemic uncertainty propagation in LCA. International Journal of Life Cycle Assessment 2013; 18 (7), 1393-1403. doi:

10.1007/s11367-013-0572-6

Corrugated Packaging Alliance. Life Cycle Assessment of U.S. Industry-Average Corrugated Product, Prepared by PE Americas and Five Winds International; 2009.

Damgaard A, Christensen T H. Recycling of Metals In: Christensen T H. Solid Waste Technology

\& Management, Volume 1 \& 2, John Wiley \& Sons, Ltd., Chichester, UK; 2010 p. 234-242. doi:

10.1002/9780470666883.ch18

EASEWASTE. Life cycle assessment tool of waste management systems. Technical University of Denmark; 2010. http://www.easewaste.dk/ [cited 02.11.13]

Ecoinvent. ecoinvent database; 2013. Available from: http://www.ecoinvent.org/ [cited 13.12.13]

EEA. European Environment Agency EEA. EN27 Electricity production by fuel; 2007. Available from: http://www.eea.europa.eu/data-and-maps/indicators/en27-electricity-production-by-fuel [cited 02.11.13].

Eisted R, Larsen A W, Christensen T H. Collection, transfer and transport of waste: accounting of greenhouse gases and global warming contribution. Waste Management \& Research 2009; 27, 73845.

ELCD. European reference Life Cycle Database (ELCD); 2013. Available from: http://elcd.jrc.ec.europa.eu/ELCD3/ [cited 02.11.13].

ETH-ESU. Eidgenössische Technische Hochschule, Gruppe Energie-Stoffe-Umwelt; 1996. Data available from: www.ecoinvent.org [cited 02.11.13].

EUROFER. European Steel Association, Eurofer database; 2000. Available from:

http://www.eurofer.be/ Data can be accessed through Gabi software. [cited 02.11.13].

European Commission. COM (2011) 21, Communication from the commission to the European parliament, the council, the European economic and social committee and the committee of the regions, A resource-efficient Europe - Flagship initiative under the Europe 2020 Strategy; 2011. Available from: http://ec.europa.eu/resource-efficient-europe/pdf/resource_efficient_europe_en.pdf [cited 02.11.13].

European Commission. Joint Research Centre - Institute for Environment and Sustainability: International Reference Life Cycle Data System (ILCD) Handbook - General guide for Life Cycle Assessment - Detailed guidance. First edition March 2010. EUR 24708 EN. Luxembourg. Publications Office of the European Union; 2010.

European Commission. Waste Management Options and Climate Change; 2001. Available from: http://ec.europa.eu/environment/waste/studies/pdf/climate_change.pdf [cited 02.11.13]. 
EAA. European Aluminum Association; 2005. Available from: http://gabi-datasetdocumentation.gabi-software.com/xml_data/sources/f4e39c11-9f94-496d-a854f04a351ee6b6_19.00.000.xml [cited 02.11.13].

Fitzgerald G C, Krones J S, Themelis N J. Greenhouse gas impact of dual stream and single stream collection and separation of recyclables. Resources, Conservation and Recycling 2012; 69, 50-56.

Franklin Associates. The Franklin US LCI 98; 1995. A Division of ERG. Data can be accessed through www.ecoinvent.org [cited 02.11.13].

GEMIS. Database Global Emissions Model for integrated Systems; 1990. Available from: http://www.iinas.org/gemis-de.html [cited 02.11.13].

Gentil E C, Damgaard A, Hauschild M, Finnveden G, Eriksson O, Thorneloe S, Kaplan P O, Barlaz M, Muller O, Matsui Y, Ii R and Christensen T H. Models for waste life cycle assessment: Review of technical assumptions, Waste Management 2010; 30, 12, 2636-2648.

Hertwich E G. Addressing biogenic greenhouse gas emissions from hydropower in LCA. Environmental Science \& Technology 2013; 47, 9604-11.

Hoornweg, D., Bhada-Tata, P., \& Kennedy, C. Environment: Waste production must peak this century. Nature 2013; 502(7473), 615-617.

IFEU. Tool for calculating greenhouse gasses in solid waste management, Institute for Energy and Environmental Research, Heidelberg; 2009. Available from:

http://www.ifeu.org/abfallwirtschaft/pdf/Manual\%20SWM-GHG\%20Calculator_2009.pdf [cited 02.11.13].

Ifu Hamburg. ifu Hamburg GmbH, Max-Brauer-Allee 50, 22765 Hamburg, Germany; 2013. Available from: http://www.umberto.de/en/ [cited 02.11.13].

IISI. Steel: The Foundation of a Sustainable Future. Sustainability Report of the World Steel Industry 2005. International Iron and Steel Institute, Brussels, Belgium; 2005.

Industry data 2.0. Industry data 2.0; 2000. Data can be accessed through www.ecoinvent.org [cited 02.11.13].

International Aluminium Institute. Life cycle assessment of aluminium: Inventory data for the primary aluminium industry, Year 2005 Update; 2007. Available from: http://www.worldaluminium.org/media/filer_public/2013/01/15/fl0000166.pdf [cited 02.11.13].

International Energy Agency (IEA). Tracking Industrial Energy Efficiency and CO2 Emissions; 2007. ISBN 978-92-64-03016-9. Available from:

http://www.iea.org/publications/freepublications/publication/tracking_emissions.pdf [cited 02.11.13]. 
International Paper. Sustainable report 2010. International Paper, 6400 Poplar Avenue, Memphis, TN 38197; 2010. Available from:

www.internationalpaper.com/US/EN/Company/Sustainability/SustainabilityReport.html [cited 02.11.13].

Interseroh. Recycling für den klimaschutz; 2007. Available from:

www.regensburg.de/sixcms/media.php/121/broschuere_recycling_fuer_den_klimaschutz.pdf [cited 02.11.13].

IPPC. Best available techniques (BAT) reference document for the manufacture of glass. Industrial emission directive 2010/75/EU; 2013.

IPPC. Reference document on best available techniques in the pulp and paper industry. Integrated Pollution Prevention and Control, European Commission, Brussels, Belgium; 2001.

ISO 14044. Environmental management - Life cycle assessment - Requirements and guidelines. International Organization for Standardization, ISO Central Secretariat, 1, ch. de la Voie-Creuse, CP 56, CH-1211 Geneva 20, Switzerland; 2006. Available from: http://www.iso.org/iso/catalogue_detail?csnumber=38498 [cited 02.11.13].

Larsen A W, Astrup T. $\mathrm{CO}_{2}$ emission factors for waste incineration: influence from source separation of recyclable materials. Waste Management 2011; 31, 1597- 1605.

Levis J W, Barlaz M A. Is Biodegradability a Desirable Attribute for Discarded Solid Waste? Perspectives from a National Landfill Greenhouse Gas Inventory Model. Environmental Science \& Technology 2011; 45, 5470-5476.

Levis J W, Barlaz M A, DeCarolis J F, Ranjithan S R. A generalized multistage optimization modeling framework for life cycle assessment-based integrated solid waste management; 2013. Environmental Modelling Software 50, 51-65.

McMillan C A and Keoleian G A. Not all primary aluminum is created equal: life cycle greenhouse gas emissions from 1990 to 2005. Environmental Science \& Technology 2009; 43, 1571-1577.

Merrild H, Larsen A W, Christensen T H. Assessing recycling versus incineration of key materials in municipal waste: The importance of efficient energy recovery and transport distances. Waste Management 2012; 32 (5), 1009-1018.

Muñoz I, Rigarlsford G, Canals L M, King H. Accounting for greenhouse gas emissions from the degradation of chemicals in the environment. International Journal of Life Cycle Assessment 2012; $18,252-262$.

PE International. GaBi software; 2013. Available from: http://www.gabi-software.com [cited 02.11.13]. 
PlasticEurope. Plastic Europe Eco profiles; 2005. Available from:

http://www.plasticseurope.org/plastics-sustainability/eco-profiles.aspx [cited 02.11.13].

PRé. Simapro LCA software; 2013. Available from: http://www.pre-sustainability.com/simaprolca-software [cited 02.11.13].

Staley B F, Barlaz M A. Composition of Municipal Solid Waste in the United States and Implications for Carbon Sequestration and Methane Yield. Journal of environmental engineering 2009; 135 (10): 901-909.

Stora Enso. Global Responsibility Report. Stora Enso Oyj, Kanavaranta 1 FI-00101 Helsinki, Finland; 2011. Available from: www.storaenso.com [cited 02.11.13].

TU Delft. IDEMAT; 2001. Available from: http://www.idemat.nl/, Data can be also be accessed through: www.ecoinvent.org [cited 02.11.13].

US EPA. Greenhouse gas emissions from management of selected materials in municipal solid waste, Final report. Prepared for the US environmental protection agency under EPA contract no. 68-W6-0029; 1998.

US EPA. Life cycle inventory data sets for material production of Aluminum, Glass, Paper, Plastic, and Steel in North America; 2003. Available from:

https://mswdst.rti.org/docs/LCI_Report_OCR.pdf [cited 02.11.13].

US LCI. U.S. Life Cycle Inventory Database; 2013. Available from:

https://www.lcacommons.gov/nrel/search [cited 02.11.13].

Waste and Resource Action Programme (WRAP). LCA of Management Options for Mixed Waste Plastics; 2008. Available from:

http://www.wrap.org.uk/sites/files/wrap/LCA\%20of\%20Management\%20Options\%20for\%20Mixe d\%20Waste\%20Plastics.pdf [cited 02.11.13].

Waste and Resource Action Programme (WRAP). Waste Resource Action Programme, Environmental benefits of recycling - an international review of life cycle comparisons for key materials in the UK recycling sector. WRAP, Banbury, United Kingdom; 2006.

Web of Knowledge. Web of knowledge website; 2013. Available from: http://wokinfo.com/ [cited 02.11.13].

Weidema B P and Wesnaes M S. Data quality management for life cycle inventories - an example of using data quality indicators. Journal of Cleaner Production 1996; 4 (3-4):167-174.

Wenzel H, Hauschild M, Alting L. Environmental Assessment of Products. Vol. 1 - Methodology, tools and case studies in product development. First edition. Chapman \& Hall, United Kingdom, Kluwer Academic Publishers, Hingham, MA, USA; 1997. 
World steel association. Steel's contribution to a low carbon future, Worldsteel position paper;

2012. Available from: http://www.worldsteel.org/publications/bookshop?bookID=26c4d914-f1594468-8933-94404015861b [cited 02.11.13].

WorldSteel. World steel Association, The white book of steel; 2012. Available from:

http://www.worldsteel.org/media-centre/press-releases/2013/White-Book-launch-online-ebook.html, ISBN 978-2-930069-67-8 [cited 02.11.13].

WorldSteel. Dataprovider World Steel; 2007. Available from: http://www.worldsteel.org/. Data can be accessed through Gabi software [cited 02.11.13].

Återvinningsindustrierna. Miljöfördelar med återvunnet material som råvara, Stockholm, Sweden; 2002. Available from:

http://www.recycling.se/MediaBinaryLoader.axd?MediaArchive_FileID=0b42810d-37da-44538c0a-34b2157844dd\&FileName=Rapport+2002.pdf [cited 02.11.13]. 